\title{
Quadriacanthus species (Monogenea: Dactylogyridae) from catfishes (Teleostei: Siluriformes) in eastern Africa: new species, new records and first insights into interspecific genetic relationships
}

Kateřina Francová ${ }^{*}$, Mária Seifertová1, Radim Blažek ${ }^{1,2}$, Milan Gelnar ${ }^{1}$, Zuheir N. Mahmoud ${ }^{3}$ and Eva Řehulková ${ }^{1}$

\begin{abstract}
Background: African catfishes of the families Bagridae and Clariidae are known to be parasitized with monogeneans of Quadriacanthus Paperna, 1961 (Dactylogyridae). The genus remains taxonomically challenging due to its speciose nature and relatively wide host range representing two fish orders, i.e. Siluriformes and Osteoglossiformes, in Africa and Asia. Here, we investigated diversity of Quadriacanthus spp. parasitizing Clarias gariepinus (Burchell), Heterobranchus bidorsalis Geoffroy Saint-Hilaire, and Bagrus docmak (Forsskål) collected in the Lake Turkana (Kenya) and Nile River Basin (Sudan). The interspecific relationships among Quadriacanthus spp. parasitizing catfishes inferred from ribosomal DNA sequences were investigated for the first time.

Methods: A combined morphological and molecular approach was used for description of the new species and for a critical review of the previously described Quadriacanthus spp., by means of phase contrast microscopic examination of sclerotized structures, and assessing the genetic divergence among the species found using rDNA sequences.

Results: Seven species (including four new) of Quadriacanthus were identified. These were as follows: Quadriacanthus aegypticus El-Naggar \& Serag, 1986, Quadriacanthus clariadis Paperna, 1961, Quadriacanthus fornicatus n. sp., Quadriacanthus pravus n. sp., and Quadriacanthus zuheiri n. sp. from Clarias gariepinus (Clariidae); Quadriacanthus mandibulatus n. sp. from Heterobranchus bidorsalis (Clariidae); and Quadriacanthus bagrae Paperna, 1979 from Bagrus docmak (Bagridae). For both 18S-ITS1 and 28S rDNA regions, Q. clariadis from a clariid fish was found to be most closely related to Q. bagrae from a bagrid host. Quadriacanthus mandibulatus n. sp. was observed to be the most distant species from the others. The separation of Q. mandibulatus n. sp. from the other species corresponds with the different morphology of its copulatory tube. The copulatory tube is terminally enlarged in Q. mandibulatus n. sp., while the tube in all other congeners studied is comparatively small and with an oblique tapering termination.

(Continued on next page)
\end{abstract}

\footnotetext{
* Correspondence: kfranc@sci.muni.cz

${ }^{1}$ Department of Botany and Zoology, Faculty of Science, Masaryk University,

Kotlárská 2, 61137 Brno, Czech Republic

Full list of author information is available at the end of the article
} 
(Continued from previous page)

Conclusions: This study contributes to a better understanding of African dactylogyrid diversity and provides the first molecular characterization of Quadriacanthus spp. The observed interspecific genetic relationships among Quadriacanthus spp. from clariids and Q. bagrae from a bagrid host suggest a possible host-switching event in the evolutionary history of the genus. Our records extend the currently known geographical range for Quadriacanthus spp. to Kenya and Sudan.

Keywords: Monogenea, Dactylogyridae, Quadriacanthus, Siluriformes, Catfishes, Africa, Lake Turkana, Nile River Basin, New species, DNA

\section{Background}

Monogenea is a diverse group of mostly ectoparasitic flatworms showing great potential as model organisms to study the ecological and evolutionary processes that drive diversification and speciation. The high host specificity shown by most monogeneans enables searches for links between the ecological characteristics of the hosts and the diversity of their parasites [1].

Among monogeneans, Quadriacanthus Paperna, 1961 (Dactylogyridae) represents one of the genera with wider host and geographical distribution. Although this genus comprises mostly gill parasites of African and Asian clariids (Siluriformes, Clariidae), one species has been recorded on bagrids (Siluriformes, Bagridae) and one species on phylogenetically distant notopterids (Osteoglossiformes, Notopteridae) in Africa [2, 3].

The genus was proposed by Paperna [4] for Q. clariadis Paperna, 1961 from the gills of Clarias gariepinus (Burchell) (syn. C. lazera) collected in Israel and characterized, in part, by having two unequal bars, each with a solid base. Kritsky \& Kulo [5] subsequently emended the diagnosis of Quadriacanthus and recognized that the ventral bar is composed of two components articulating medially. Despite the work of these authors, Dubey et al. [6] established Anacornuatus Dubey, Gupta \& Agarwal, 1992 for those species of Quadriacanthus that possess a two-piece ventral bar instead of a single-piece ventral bar, as indicated by Paperna [4]. They were evidently unaware of the work of Kritsky \& Kulo [5] and hence erred in proposing the new genus. Consequently, Lim et al. [2], who listed 24 species of Quadriacanthus parasitizing Clariidae (Clarias spp. and Heterobranchus spp.) and African Bagrus spp., plus one Quadriacanthus species of doubtful validity, infecting tilapia (see also [5]), synonymized Anacornuatus with Quadriacanthus. However, these authors were not able to ascertain the validity of the two species assigned to Anacornuatus and considered them as species inquirendae. Tripathi et al. [7] added generic characters, redefined the dorsal bar as " $T$ or Y-shaped with mid-posterior process", and limited the taxon to 25 species (including Anacornuatus postbifidus Dubey, Gupta \& Agarwal, 1992 as a new combination within Quadriacanthus). The recent descriptions of three new species from Clarias submarginatus Peters by Bahanak et al. [8] brings the number of Quadriacanthus species from siluriform hosts to 28. Nack et al. [3] revealed the presence of a species of Quadriacanthus on a fish host belonging to the Notopteridae (Osteoglossiformes). This finding extends the host range of species of Quadriacanthus to a new family (Notopteridae) and even a new order (Osteoglossiformes).

In a recent survey of monogeneans parasitizing catfishes from Kenya and Sudan, we recovered three described $(Q$. aegypticus El-Naggar \& Serag, 1986, Q. clariadis Paperna, 1961 and Q. bagrae Paperna, 1979) and four new species of Quadriacanthus. We thus aimed to describe these four species and determine their relationships to congeners based on the partial 18S, entire ITS1, and partial $28 \mathrm{~S}$ rDNA sequences.

\section{Methods}

\section{Fish collection}

Catfish hosts Bagrus docmak (Forsskål) (Bagridae), Clarias gariepinus (Burchell) and Heterobranchus bidorsalis Geoffroy Saint-Hilaire (Clariidae) (all autochthonous fishes) were collected by hook-and-line or beach seine net, or purchased at local fish markets in five localities in Kenya (Lake Turkana) and Sudan (White and Blue Nile River) during the period 2008-2014 (Table 1; Fig. 1). Fish hosts were identified using the keys given by Bailey [9] and Hopson \& Hopson [10]. Scientific and common names of fishes are those provided in FishBase [11] and verified in Eschmeyer et al. [12].

\section{Parasite collection and identification}

The gills of freshly killed fishes were extracted and examined in bottled water under a dissecting microscope. Live monogeneans were individually picked from the gills with fine needles and immediately processed. Some specimens were prepared for morphological studies following Musilová et al. [13]. Briefly, they were flattened using coverslip pressure in order to best expose their hard parts, and fixed with a mixture of glycerine and ammonium picrate (GAP). Specimens collected for DNA analyses were bisected using fine needles under a dissecting microscope. Subsequently, one half of the 
Table 1 Localities from which siluriform species were collected during 2008-2014

\begin{tabular}{|c|c|c|c|}
\hline Locality number & Locality name & Coordinates & Year of collection \\
\hline 1 & Kalokol - Fishing Lodge, Lake Turkana, Kenya & $3^{\circ} 33^{\prime} 18.26^{\prime \prime} \mathrm{N}, 35^{\circ} 54^{\prime} 56.03^{\prime \prime} \mathrm{E}$ & 2008,2009 \\
\hline 2 & Loyingalani - El Molo Bay, Lake Turkana, Kenya & $2^{\circ} 49^{\prime} 45.55^{\prime \prime} \mathrm{N}, 36^{\circ} 41^{\prime} 55.32^{\prime \prime} \mathrm{E}$ & 2008,2009 \\
\hline 3 & Todonyang - Omo River Delta, Lake Turkana, Kenya & $4^{\circ} 27^{\prime} 6.37^{\prime \prime} \mathrm{N}, 35^{\circ} 56^{\prime} 15.44^{\prime \prime} \mathrm{E}$ & 2008, 2009 \\
\hline 4 & Fishmarket in Kosti, White Nile, Sudan & $13^{\circ} 10^{\prime} 18.58^{\prime \prime} \mathrm{N}, 32^{\circ} 40^{\prime} 19.24^{\prime \prime} \mathrm{E}$ & 2010,2014 \\
\hline 5 & Fishmarket in Sennar, Blue Nile, Sudan & $13^{\circ} 32^{\prime} 31.09^{\prime \prime} \mathrm{N}, 33^{\circ} 37^{\prime} 15.79^{\prime \prime} \mathrm{E}$ & 2010,2014 \\
\hline
\end{tabular}

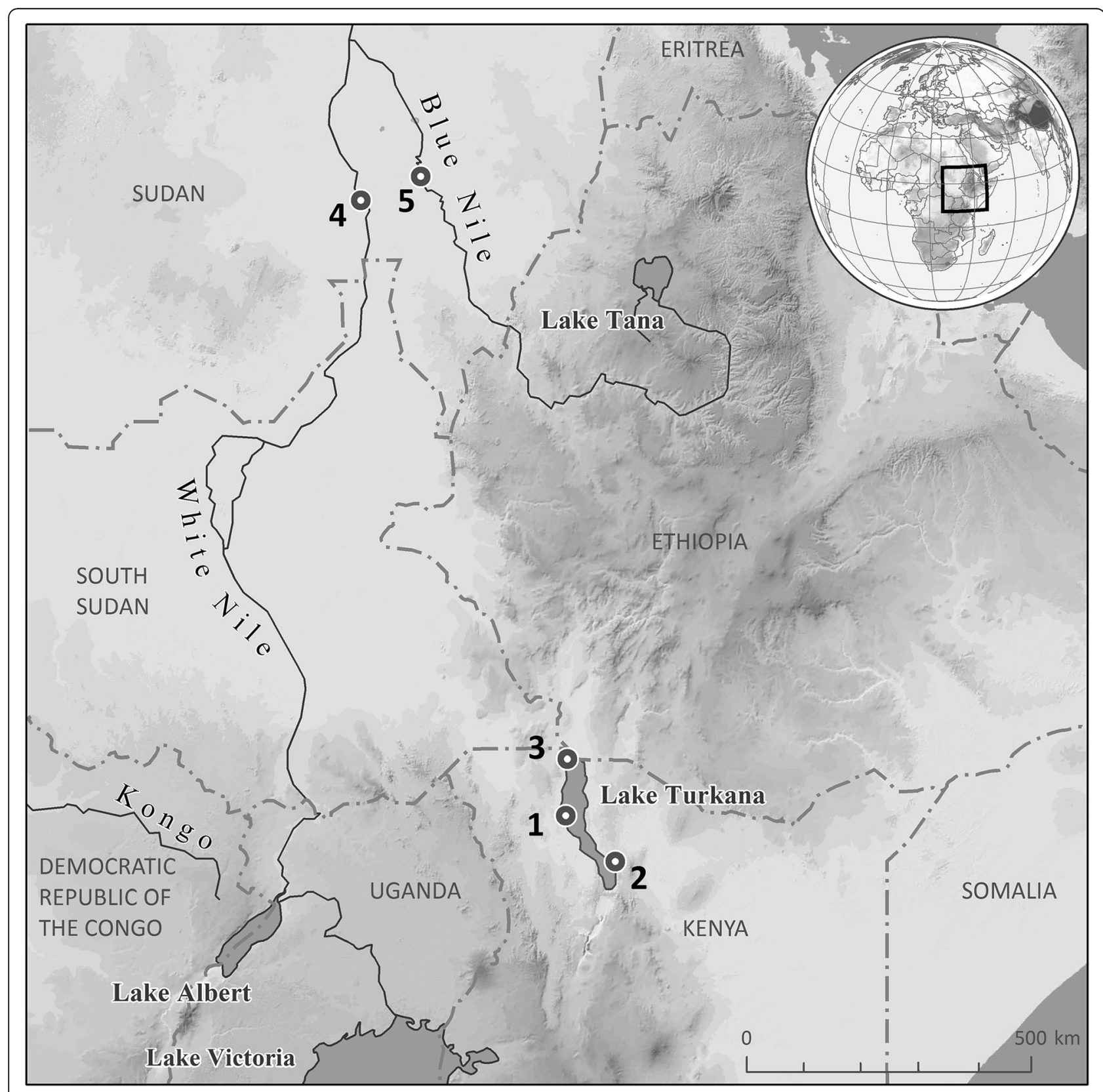

Fig. 1 Map of the localities from which siluriform species were collected during 2008-2014 (see also Table 1) 
body (either the posterior part with haptoral sclerites or anterior part containing the male copulatory organ) was fixed in 96\% ethanol for later molecular analysis; the other body half was completely flattened under coverslip pressure and fixed with GAP for species identification. The body half in GAP was deposited (one per species) as a hologenophore, i.e. a voucher specimen from which a molecular sample is directly derived (see [14] for terminology). Parasite specimens collected in Kenya were not used for molecular analysis.

The mounted monogenean specimens (or their parts) were studied using an Olympus BX 61 microscope equipped with phase contrast optics, and drawings were made with the aid of a drawing attachment. Measurements, all in micrometres, were taken using digital image analysis (Stream Motion, version 1.9.2) and are presented as the range followed by the mean and the number $(n)$ of specimens measured in parentheses. The dimensions of the body and haptor were obtained from unflattened specimens as the longest measurements in dorsoventral view; measurements of the sclerotized structures (the haptoral and reproductive hard parts) were taken from specimens flattened under coverslip pressure, facilitated by the blotting of excess water with a filter paper. The schemes of measurement for the hard structures are shown in Fig. 2; in essence, the method of measuring the anchors follows the procedures outlined by Řehulková \& Gelnar [15]. The numbering of hook pairs (in Roman numerals) follows that recommended by Mizelle [16]. The male copulatory organ is henceforth abbreviated to MCO. For comparative purposes, specimens of some previously described species were examined: Quadriacanthus agnebiensis N’Douba, Lambert \& Euzet, 1999 (MNHN 572 HF Tk 89); Quadriacanthus clariadis Paperna, 1961 (MRAC 37.160); Quadriacanthus numidus Kritsky \& Kulo, 1988 (MNHN 146 HF); Quadriacanthus thysi N'Douba, Lambert \& Euzet, 1999 (MNHN 577 HF Tk 94 and 576 HF Tk 93; and MRAC 37416). Note that the authorities of the new taxa described below are Francová \& Řehulková (according to International Code of Zoological Nomenclature [17]).

\section{DNA extraction, PCR amplification and sequencing}

DNA was extracted from 2 to 6 individuals of each collected species using a DNeasy ${ }^{\circ}$ Blood \& Tissue Kit (Qiagen, Hilden, Germany) following the manufacturer's instructions. DNA was stored in $\mathrm{AE}$ buffer at $-20{ }^{\circ} \mathrm{C}$. Two nuclear ribosomal DNA fragments were used in our analysis: fragment spanning partial 18S rDNA (18S) and entire internal transcribed spacer 1 (ITS1), and fragment of partial nuclear 28S rDNA (28S). Until now, only two $28 \mathrm{~S}$ sequences for Quadriacanthus kobiensis $\mathrm{Ha}$, 1968 (EF100545, AY841874) and one 18S-ITS1 fragment for Quadriacanthus sp. (HG491496) had been deposited in GenBank. The partial $28 \mathrm{~S}$ fragment was amplified using primers $\mathrm{C} 1$ (forward; 5'-ACC CGC TGA ATT TAA GCA T-3') and D2 (reverse; 5'-TGG TCC GTG TTT CAA GAC-3') [18]. The 18S-ITS1 fragment was amplified in one round using primers $\mathrm{S} 1$ (forward, 5'ATT CCG ATA ACG AAC GAG ACT-3') [19] and IR8 (reverse, 5'-GCT AGC TGC GTT CTT CAT CGA-3'), that anneal to the $18 \mathrm{~S}$ and $5.8 \mathrm{~S}$ rDNA genes, respectively [20]. PCRs were performed according to Mendlová et al. [21]. The PCR products were electrophoresed on a Gold View strained agarose gel (2\%) and then successful PCRs, in which a single fragment was amplified, were purified using High Pure PCR Product Purification Kit (Roche, Mannheim, Germany). The purified PCR products were sequenced for both strands with the same primers as used in the amplification. Sequencing was carried out using BigDye ${ }^{\oplus}$ Terminator v3.1 Cycle Sequencing Kit and an Applied Biosystems 3130 Genetic Analyzer. Nucleotide sequences of the 18S-ITS1 and partial $28 \mathrm{~S}$ regions were assembled and edited using Sequencher software (Gene Codes Corporation, Ann Arbor, MI, USA). The final sequences were deposited in the GenBank database under accession numbers KX713993-KX713998 and KX685951-KX685956.

\section{Sequence and phylogenetic analysis}

Because no significant differences were found between $18 \mathrm{~S}$ and ITS1 sequence data (partition homogeneity test, $P=1.00$ ), further analyses were performed based on concatenated 18S-ITS1 sequences. Two datasets (18SITS1 and 28S) were used to estimate the interspecific relationships among the Quadriacanthus species. All corrected 18S-ITS1 and 28S sequences were aligned using ClustalW [22] and improved manually using the program BioEdit version 7.1.11 [23]. Alignments were then trimmed automatically using TrimAl v.1.3 [24]. Calculations of genetic distances (Kimura 2-parameter [25]) among sequences of Quadriacanthus species were carried out in MEGA 7 [26].

Maximum likelihood analyses were conducted using MEGA 7 [26] with 1000 rapid bootstrap replicates. Data were modelled according to the $\mathrm{K} 2+\mathrm{G}$ model. Phylogenetic trees were rooted by including available data from GenBank: Schilbetrema sp. (HG491495) isolated from Schilbe intermedius Rüppell in Africa for the 18S-ITS1 dataset, and Schilbetrema sp. (KP056243) isolated from Pareutropius debauwi (Boulenger) in West Africa for the $28 \mathrm{~S}$ dataset. Quadriacanthus sp. (HG491496) isolated from Heterobranchus bidorsalis Geoffroy SaintHilaire in Senegal (West Africa) was also included in the 18S-ITS1 phylogenetic analysis, and Q. kobiensis Ha, 1968 (AY841874) isolated from Clarias batrachus (Linnaeus) in China was used in the $28 \mathrm{~S}$ phylogenetic analysis. 


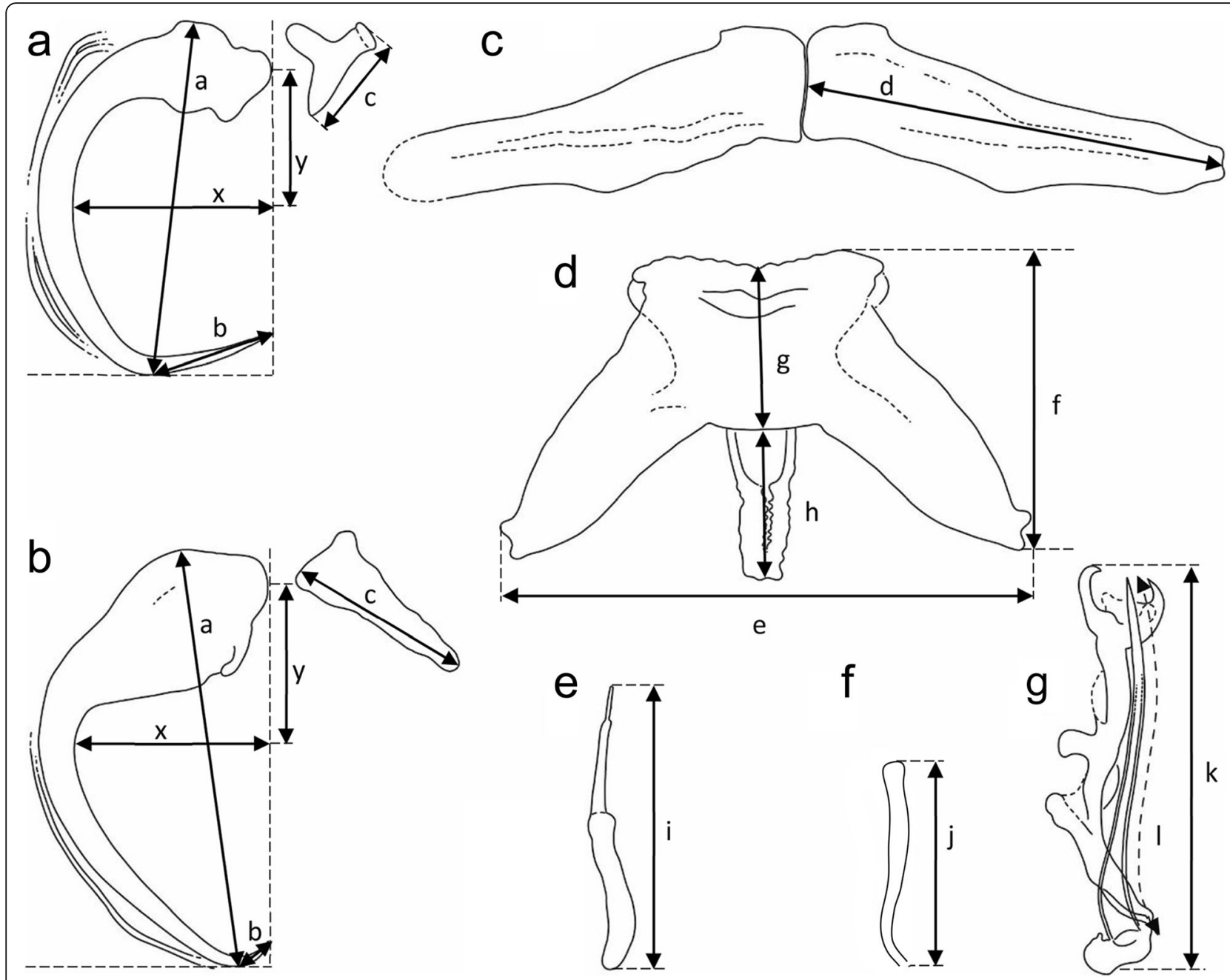

Fig. 2 Scheme of measurement for sclerotized structures of Quadriacanthus spp. a Ventral anchor. b Dorsal anchor ( $a$, total length; $b$, point length; $c$, total length of accessory sclerite; $x / y$, curvature of shaft). $\mathbf{c}$ Ventral bar ( $d$, component length). $\mathbf{d}$ Dorsal bar (e, total length; $f$, total width excluding the process; $g$, thickness at mid-region; $h$, process length). e Hook (i, total length). f Vagina (j, total length). g MCO ( $k$, total length; $l$, trace length of copulatory tube)

\section{Results}

Our investigation of the monogeneans from the gills of three catfish species revealed the presence of three previously described and four new species of Quadriacanthus. Bagrus docmak (Bagridae) and Heterobranchus bidorsalis (Clariidae) were each found to harbour one Quadriacanthus species, Q. bagrae and Q. mandibulatus $\mathrm{n}$. sp., respectively. Five Quadriacanthus species were found to infect Clarias gariepinus (Clariidae): Q. aegypticus, Q. clariadis, Q. fornicatus n. sp., Q. pravus n. sp., and $Q$. zuheiri $\mathrm{n}$. sp. All the species found are morphologically characterized and described below.

Family Dactylogyridae Bychowsky, 1933

Genus Quadriacanthus Paperna, 1961

Quadriacanthus aegypticus El-Naggar \& Serag, 1986
Syn. Anacornuatus aegypticus (El-Naggar \& Serag, 1986)

Dubey, Gupta \& Agarwal, 1992

Type-host and locality: Clarias gariepinus (Burchell) (syn. C. lazera) (Clariidae), Lake Manzala and the Demietta branch of the River Nile, Dakahlia Governorate, Egypt [27]. Host: Clarias gariepinus (present study).

Localities: Lake Turkana, Kenya (localities 1-3); Nile River Basin, Sudan (localities 4, 5) (present study).

Site in host: Gill lamellae.

Other records: C. gariepinus (syn. C. lazera), Nile River near Cairo, Egypt [5]; C. gariepinus, Lake Kariba, Zimbabwe [28]; C. gariepinus, River Nile in the Helwan locality, south Cairo, Egypt [29]; C. gariepinus, Nwanedi-Luphephe Dams, Limpopo River System, South Africa [30]; C. gariepinus, Vaal Dam, Gauteng Province, South Africa [31]; C. gariepinus, Lake Tana (Bahir Dar), Ethiopia [32]. 
Voucher material: MNHN HEL625 (1 specimen; locality 4); MNHN HEL626 (2 specimens; locality 1); MNHN HEL627 (1 specimen; locality 3); IPCAS M-632 (1 specimen from locality $1 ; 1$ specimen from locality 5 ).

\section{Measurements}

[Based on 10 flattened and 3 unflattened specimens in GAP; Fig. 3]. Body length 475-569 (513; $n=3$ ); greatest width 80-125 $(108 ; n=3)$. Haptor 95-100 $(97 ; n=3)$ long, 110-155 (136; $n=3$ ) wide. Ventral anchor: $\mathrm{a}=33-37$ (35; $n=10) ; \mathrm{b}=11-13(12 ; n=10) ; \mathrm{c}=9-11(10 ; n=10) ; \mathrm{x} /$ $\mathrm{y}=1.2-1.7(1.4 ; n=10)$. Dorsal anchor: $\mathrm{a}=40-44(42$; $n=10) ; \mathrm{b}=3-5(4 ; n=10) ; \mathrm{c}=16-21(19 ; n=10) ; \mathrm{x} /$ $\mathrm{y}=1.1-1.2(1.1 ; n=10)$. Ventral bar: $\mathrm{d}=40-46(43$; $n=10)$. Dorsal bar: $\mathrm{e}=39-52(49 ; n=10) ; \mathrm{f}=21-31(28$; $n=10) ; \mathrm{g}=10-17(15 ; n=10) ; \mathrm{h}=14-17(15 ; n=10)$. Hooks: 7 pairs; $i=11-29$ (17; $n=10)$ : hook I 16-19 (17; $n=10)$; hooks II-V 11-15 (13; $n=10)$; hook VI 26-29 $(29 ; n=10)$; hook VII $18-19(18 ; n=10)$. Vagina: slightly sclerotized; $\mathrm{j}=17-21(19 ; n=10)$. MCO: $\mathrm{k}=39-44$ (41; $n=10) ; 1=36-40(38 ; n=10)$.

\section{Differential diagnosis}

The present specimens closely fit the characters of the original description of Q. aegypticus by El-Naggar \& Serag [27] as well as the drawings/measurements provided by Kritsky \& Kulo [5] and Douëllou \& Chishawa [28] and there is little doubt that they are conspecific. However, it should be mentioned that in the original paper by Douëllou \& Chishawa [28] the illustrations of Q. aegypticus were mixed with those of another Quadriacanthus species; their figure 2 (identified as the haptoral structures, $\mathrm{MCO}$ and vagina of $Q$. aegypticus) clearly represents the sclerotized structures (actually without depiction of a vagina) of another species of Quadriacanthus, most probably those of Q. clariadis, although the morphometrical characteristics of the sclerotized structures correspond to those originally described for Q. aegypticus. Also, Douëllou \& Chishawa's [28] figure 1 (identified as the sclerotized structures of Q. bagrae) and figure 2 are identical (see also remarks to Q. bagrae); indeed, figure 2 was later replaced with the correct version (i.e. illustrating the sclerotized structures of the real Q. aegypticus) as an erratum to Douëllou \& Chishawa's [28] original paper.

Quadriacanthus aegypticus is most similar to $Q$. clariadis on the basis of the morphology of the haptoral sclerites. It differs from the latter species by having (i) noticeably larger ventral anchors in relation to the ventral bar; (ii) a ventral anchor with an elongated shaft (the shaft of the ventral anchor is comparatively shorter in Q. clariadis); (iii) a sclerotized vagina; and (iv) an accessory piece with two claw-like hooks serving as a guide for the distal portion of the copulatory tube and a medial part modified into two protruding diverticula.

\section{Quadriacanthus bagrae Paperna, 1979}

Syn. Quadriacanthus clariadis bagrae Paperna, 1979

Type-host and locality: Bagrus docmak (Forsskål) (syn. B. docmac) (Bagridae), Lake Victoria, Uganda [33].

Host: Bagrus docmak (present study).

Locality: Nile River Basin, Sudan (locality 5) (present study). Site in host: Gill lamellae.

Other records: Bagrus docmak (syn. B. docmac), AlbertNile near Chobe, Uganda [33]; Bagrus bajad (syn. B. bayad), Lake Albert, Uganda [33]; Bagrus orientalis, River Ruaha, Tanzania [33]; Clarias gariepinus (syn. C. lazera), River Nile near Cairo, Egypt [5]; Clarias gariepinus, Lake Kariba, Zimbabwe [28]; C. gariepinus, River Gomti, Lucknow, State of Uttar Pradesh, India [7].

Voucher material: MNHN HEL628 (1 specimen; locality 5); MNHN HEL629 (1 specimen; locality 5); IPCAS M-633 (2 specimens; locality 5). Hologenophore: MNHN HEL641 (locality 5).

Representative DNA sequences: 18S-ITS1 rDNA (GenBank acc. no. KX713993) and 28S rDNA (GenBank acc. no. KX685951) (see also Table 2).

\section{Measurements}

[Based on 10 flattened and 3 unflattened specimens in GAP; Fig. 4]. Body length 781-838 $(815 ; n=3)$; greatest width 156-194 (171; $n=3)$. Haptor 100-124 (109; $n=3)$ long, $161-194$ (179; $n=3)$ wide. Ventral anchor: $\mathrm{a}=27-33(30 ; n=10) ; \mathrm{b}=9-14(12 ; n=10) ; \mathrm{c}=8-11$ $(9 ; n=10) ; \mathrm{x} / \mathrm{y}=1.1-1.6(1.3 ; n=10)$. Dorsal anchor: $\mathrm{a}=37-43(40 ; n=10) ; \mathrm{b}=8-9(9 ; n=10) ; \mathrm{c}=16-18$ $(17 ; n=10) ; \mathrm{x} / \mathrm{y}=0.9-1.3(1.2 ; n=10)$. Ventral bar: $\mathrm{d}=47-57(52 ; n=10)$. Dorsal bar: $\mathrm{e}=58-73(64 ;$ $n=10) ; \mathrm{f}=26-33(29 ; n=10) ; \mathrm{g}=17-23(20 ; n=10)$; $\mathrm{h}=12-15(13 ; n=10)$. Hooks: 7 pairs; $i=12-25(15$; $n=3)$ : hook I 14-16 (15; $n=3)$; hooks II-V 12-16 (14; $n=3)$; hook VI 21-25 (23; $n=10)$; hook VII 13-15 (15; $n=3$ ). Vagina: not observed. MCO: $\mathrm{k}=32-35$ (34; $n=10) ; 1=29-33(31 ; n=10)$.

\section{Differential diagnosis}

This species was elevated from subspecies status under Q. clariadis and adequately redescribed by Kritsky \& Kulo [5]. The morphology and measurements of our specimens generally correspond with the redescription and later characterization of this species by Tripathi et al. [7]. Small differences were observed in the morphology of the hooks. However, the shapes of the hooks fall within the variation observed in our series. In individual specimens, the shanks of hooks appear to be more or less robust. The report of Q. bagrae by Douëllou \& 


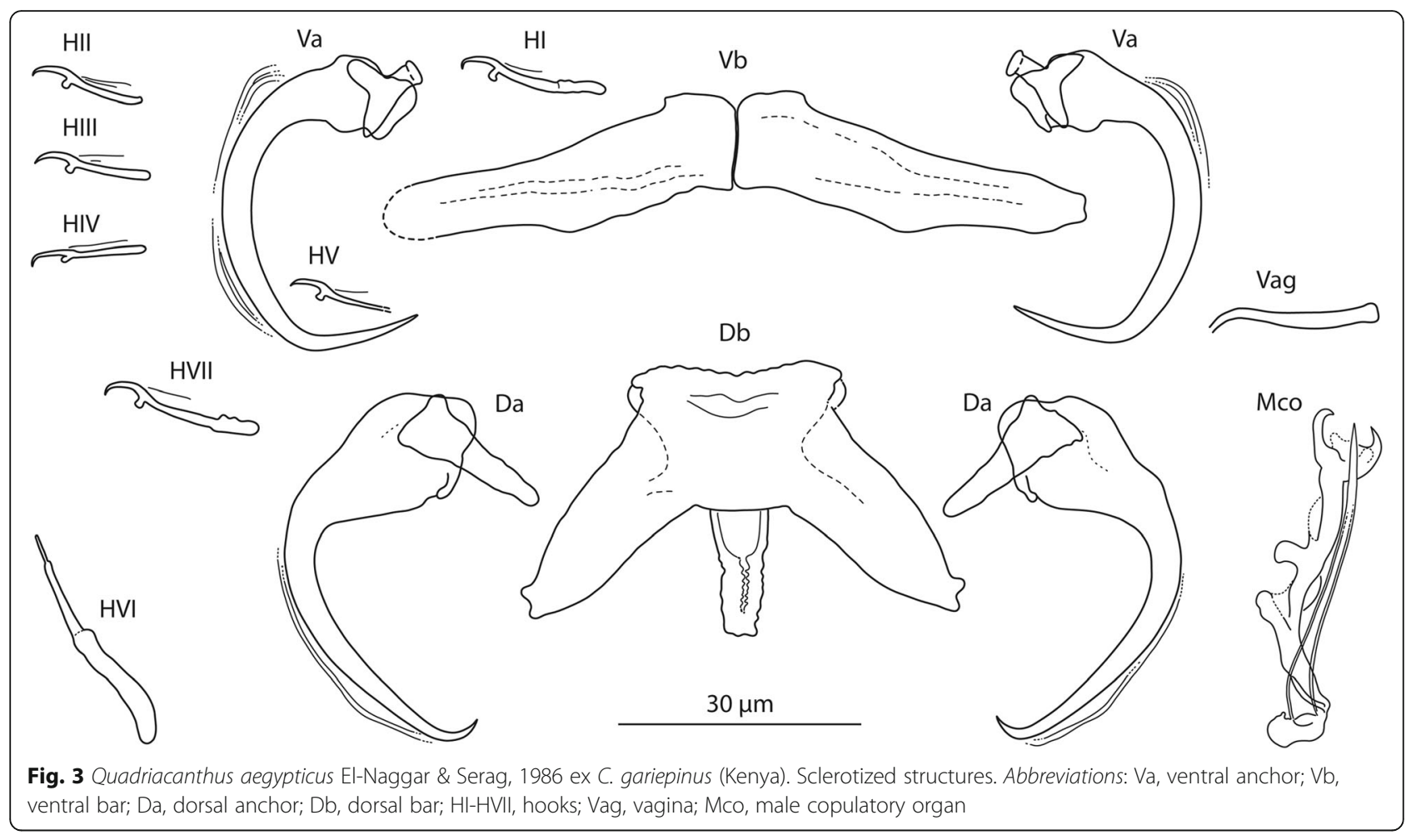

Chishawa [28] is erroneous because their drawings and measurements of the haptoral structures and $\mathrm{MCO}$ suggest that these authors were dealing with another Quadriacanthus species, most probably with Q. clariadis. Their depiction of the sclerotized structures of "Q. bagrae" (figure 1) shows a ventral bar with elongated arms (each component is more than twice longer than the total length of the ventral anchor, while it is less than twice longer in $Q$. bagrae) and a dorsal anchor with an elongated bent shaft and short point (in Q. bagrae, the dorsal anchor has a short curved shaft and a moderate point), all of which are characters consistent with specimens identified as Q. clariadis by El-Naggar \& Serag [34], Kritsky \& Kulo [5], Tripathi et al.
[7], and the present study. Moreover, Douëllou \& Chishawa [28] themselves supported our opinion by stating that the hooklets (= hooks) of their specimens were similar to those of Q. clariadis rather than to those of Q. bagrae. According to our observations, the morphology of $Q$. bagrae and $Q$. clariadis male copulatory organ is very similar; the morphology of haptoral sclerites, however, clearly differs between the two Quadriacanthus species.

\section{Molecular characterization}

The sequence of the 18S-ITS1 region of Q. bagrae was 921 bp long, of which 515 bp corresponded to the partial

Table 2 List of Quadriacanthus species used in this study, including their host species, locality (with number in parentheses), total number of isolates and GenBank accession numbers for 18S-ITS1 and 285 sequences

\begin{tabular}{|c|c|c|c|c|c|}
\hline Parasite species & Host species & Locality of collection $^{a}$ & Isolates & 18S-ITS1 & 285 \\
\hline Q. aegypticus & Clarias gariepinus & $\mathrm{LT}(1,2,3) ; \mathrm{WN}(4) ; \mathrm{BN}(5)$ & - & - & - \\
\hline Q. bagrae & Bagrus docmak & $\mathrm{BN}(5)$ & 3 & KX713993 & KX685951 \\
\hline Q. clariadis & Clarias gariepinus & $\operatorname{LT}(1,3) ; \mathbf{W N}(4) ; \mathrm{BN}(5)$ & 6 & KX713994 & KX685952 \\
\hline Q. fornicatus n. sp. & Clarias gariepinus & WN (4); BN (5) & 3 & KX713995 & KX685953 \\
\hline Q. mandibulatus n. sp. & Heterobranchus bidorsalis & $\mathrm{LT}(3) ; \mathbf{B N}(\mathbf{5})$ & 5 & KX713996 & KX685954 \\
\hline Q. pravus n. sp. & Clarias gariepinus & WN (4); BN (5) & 3 & KX713997 & KX685955 \\
\hline Q. zuheiri n. sp. & Clarias gariepinus & WN (4); BN (5) & 2 & KX713998 & KX685956 \\
\hline
\end{tabular}

Abbreviations: LT Lake Turkana, Kenya, WN White Nile (Kosti), Sudan, BN Blue Nile (Sennar), Sudan

a Localities where specimens were collected for molecular analysis are shown in bold 




Fig. 4 Quadriacanthus bagrae Paperna, 1979 ex B. docmak (Sudan). Sclerotized structures. Abbreviations: Va, ventral anchor; Vb, ventral bar; Da, dorsal anchor; Db, dorsal bar; HI-HVII, hooks; Mco, male copulatory organ

$18 \mathrm{~S}$ rDNA region and $406 \mathrm{bp}$ corresponded to the entire ITS1 region. The sequence of the partial $28 \mathrm{~S}$ region was 777 bp long. No intraspecific variability was found in 18SITS1 or $28 \mathrm{~S}$ sequences.

\section{Quadriacanthus clariadis Paperna, 1961}

Syn. Quadriacanthus clariadis clariadis Paperna, 1979

Type-host and locality: Clarias gariepinus (Burchell) (syn. C. lazera) (Clariidae), Lake Galilee, Israel [4].

Host: Clarias gariepinus (present study).

Localities: Lake Turkana, Kenya (localities 1, 3); Nile River Basin, Sudan (localities 4, 5) (present study).

Site in host: Gill lamellae.

Other records: Clarias gariepinus (syn. C. lazera), Bahr Mouis, River Nile near Zagazig, Egypt [35], Lake Manzala and Demietta Branch, River Nile near Mansoura, Egypt [34], River Nile near Cairo, Egypt [5]; C. gariepinus, River Gomti, Lucknow, State of Uttar Pradesh, India [7]; C. gariepinus, Nwanedi-Luphephe Dams, Limpopo River System, South Africa [30].

Voucher material: MNHN HEL627 (1 specimen; locality 3); MNHN HEL630 (1 specimen; locality 5); MNHN HEL631 (1 specimen; locality 4); MNHN HEL632 (2 specimens; locality 1); IPCAS M-262 (1 specimen from locality $5 ; 2$ specimens from locality 4; 1 specimen from locality 3). Hologenophore: MNHN HEL642 (locality 5).
Comparative material examined: Voucher specimen of Quadriacanthus clariadis Paperna, 1961 (MRAC 37.160).

Representative DNA sequences: 18S-ITS1 rDNA (GenBank acc. no. KX713994) and 28S rDNA (GenBank acc. no. KX685952) (see also Table 2).

\section{Measurements}

[Based on 10 flattened and 3 unflattened specimens in GAP; Fig. 5]. Body length 491-564 (518; $n=3)$; greatest width $89-115(100 ; n=3)$. Haptor $68-119(89 ; n=3)$ long, $113-151(131 ; n=3)$ wide. Ventral anchor: $\mathrm{a}=28-31(29 ; n=10) ; \mathrm{b}=10-13(11 ; n=10) ; \mathrm{c}=7-10$ $(8 ; n=10) ; \mathrm{x} / \mathrm{y}=1.1-1.9(1.4 ; n=10)$. Dorsal anchor: $\mathrm{a}=45-51(48 ; n=10) ; \mathrm{b}=5-7(6 ; n=10) ; \mathrm{c}=15-20$ $(17 ; n=10) ; \mathrm{x} / \mathrm{y}=0.9-1.0(1.0 ; n=10)$. Ventral bar: $\mathrm{d}=53-64(60 ; n=10)$. Dorsal bar: $\mathrm{e}=54-65(60$; $n=10) ; \mathrm{f}=29-37(32 ; n=10) ; \mathrm{g}=13-19(17 ; n=10)$; $\mathrm{h}=13-16(15 ; n=10)$. Hooks: 7 pairs; $i=12-39(18$; $n=10)$ : hook I $18-22(20 ; n=10)$; hooks II-V $12-15$ (14; $n=10)$; hook VI $33-39(35 ; n=10)$; hook VII 15 $16(16 ; n=10)$. Vagina: not observed. MCO: $\mathrm{k}=26-28$ $(27 ; n=10) ; 1=24-27(26 ; n=10)$.

\section{Differential diagnosis}

This species was adequately redescribed by Kritsky \& Kulo [5]. Examination of the voucher specimen (MRAC 37.160) showed that our specimens are conspecific with this material. The morphology of the 


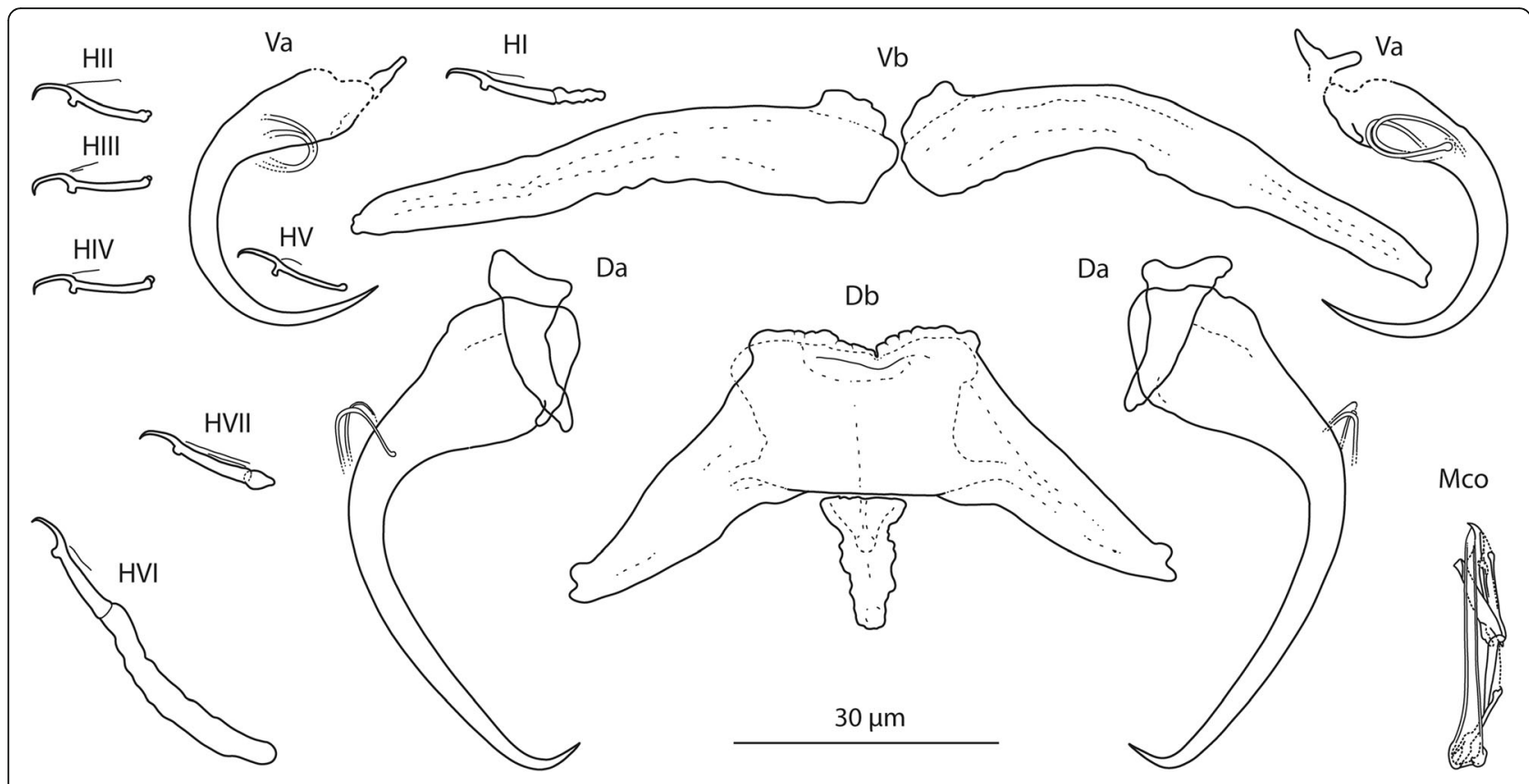

Fig. 5 Quadriacanthus clariadis Paperna, 1961 ex C. gariepinus (Sudan). Sclerotized structures. Abbreviations: Va, ventral anchor; Vb, ventral bar; Da, dorsal anchor; Db, dorsal bar; HI-HVII, hooks; Mco, male copulatory organ

sclerotized structures of our specimens also corresponds to that observed by Tripathi et al. [7] Molnar \& Mossalam's [35] report of Quadriacanthus clariadis contains photographs indicating that the authors found two Quadriacanthus species, i.e. Q. clariadis and $Q$. aegypticus, but were not able to distinguish between them (see [5]). Quadriacanthus clariadis resembles a number of congeners: $Q$. aegypticus El-Naggar \& Serag, 1986; Q. agnebiensis N'Douba, Lambert \& Euzet, 1999; Q. allobychowskiella Paperna, 1979; and Q. longifilisi N'Douba, Lambert \& Euzet, 1999) [27, 33, 36] by its having a ventral anchor with a curved shaft and long point, a dorsal anchor with an elongated bent shaft and short point, and an $\mathrm{MCO}$ composed of a straight tapered copulatory tube and an accessory piece with terminal hook(s). The differentiation of Q. clariadis and $Q$. aegypticus is provided in the remarks for the latter species. Quadriacanthus allobychowskiella is easily separated from Q. clariadis by its dorsal anchor having a large accessory sclerite. In Q. agnebiensis and Q. longifilisi, the hooks of pair VII are markedly longer that those of the corresponding pair in $Q$. clariadis.

\section{Molecular characterization}

The combined 18S-ITS1 sequence of Q. clariadis was 920 bp long. This sequence included 514 bp of the partial 18S rDNA region and the complete $406 \mathrm{bp}$ long
ITS1 region. The sequence of the partial $28 \mathrm{~S}$ region was 845 bp long. No intraspecific variability was found in the 18S-ITS1 and 28S sequences.

Quadriacanthus fornicatus Francová \& Řehulková n. sp.

Type-host: Clarias gariepinus (Burchell) (Clariidae).

Type-locality: Nile River Basin, Sudan (locality 5).

Other locality: Nile River Basin, Sudan (locality 4).

Type-material: Holotype: MNHN HEL633. Paratypes:

MNHN HEL634 (1 specimen); IPCAS M-634 (1 specimen).

Voucher material: MNHN HEL639 (2 specimens; locality 4); IPCAS M-634 (2 specimens; locality 4). Hologenophore: MNHN HEL643 (locality 5).

Site in host: Gill lamellae.

Representative DNA sequences: 18S-ITS1 rDNA (GenBank acc. no. KX713995) and 28S rDNA (GenBank acc. no. KX685953) (see also Table 2).

ZooBank registration: To comply with the regulations set out in article 8.5 of the amended 2012 version of the International Code of Zoological Nomenclature (ICZN) [37], details of the new species have been submitted to ZooBank. The Life Science Identifier (LSID) of the article is urn:lsid:zoobank.org:pub:ADCB9E56E8F1-48B6-AD21-BBA5E52D0B39. The LSID for the new name Quadriacanthus fornicatus n. sp. is urn:lsid: zoobank.org:act:6C76112A-B9EA-45E4-9DBB-96B373 8A12CF. 
Etymology: The specific name is derived from Latin (fornicatus $=$ arched, vaulted) and refers to the shape of the dorsal anchor shaft.

\section{Description}

[Based on 7 flattened and 2 unflattened specimens in GAP; Fig. 6]. Body length 384-404 $(394 ; n=2)$; greatest width $75-84(80 ; n=2)$. Haptor $77-84(80 ; n=2)$ long, 84-95 $(89 ; n=2)$ wide. Ventral anchor with moderate base, curved shaft, long point; accessory sclerite small, with subequal wings; $\mathrm{a}=26-31(28 ; n=7) ; \mathrm{b}=11-13$ $(12 ; n=7) ; \mathrm{c}=7-8(7 ; n=5) ; \mathrm{x} / \mathrm{y}=1.0-1.3(1.2 ; n=7)$. Dorsal anchor with broad base, curved shaft, long point; accessory sclerite moderate, with poorly differentiated wings; $\mathrm{a}=32-39(35 ; n=7) ; \mathrm{b}=12-13(12 ; n=7)$; $\mathrm{c}=9-14(12 ; n=7) ; \mathrm{x} / \mathrm{y}=0.9-1.2(1.1 ; n=7)$. Ventral bar composed of two elongated components; $d=44-54$ $(49 ; n=5)$. Dorsal bar with small anterior shield; midposterior process trapeziform, with uneven margins; $\mathrm{e}=42-64(54 ; n=6) ; \mathrm{f}=17-33(27 ; n=6) ; \mathrm{g}=8-14$ $(12 ; n=7) ; \mathrm{h}=9-13(12 ; n=7)$. Hooks: 7 pairs, dissimilar in size; $i=12-29(15 ; n=5)$ : hook I 13-17 (15; $n=7)$, hooks II-V 12-14 (13; $n=5)$, hook VI 25-29 $(27 ; n=7)$, hook VII $13-14(14 ; n=6)$. Vagina not observed. MCO comprising copulatory tube and accessory piece; $\mathrm{k}=23-29(26 ; n=7)$. Copulatory tube straight; base simple, without thickened margin or flange; $1=22-26(24 ; n=7)$. Accessory piece basally articulated to the copulatory tube in the form of a spike-like structure; medial part lightly sclerotized; distal part a hook-like structure with broader base.

\section{Differential diagnosis}

Quadriacanthus fornicatus $\mathrm{n}$. sp. could be confused with Q. simplex, a species described on Heterobranchus isopterus in Ivory Coast by N'Douba et al. [36], by having nearly identical haptoral sclerites. However, these species are easily differentiated by the comparative morphology of the MCO. The accessory piece of the MCO in Q. simplex is noticeably simpler than that in the new species.

\section{Molecular characterization}

The combined 18S-ITS1 sequence of Q. fornicatus $\mathrm{n}$. $\mathrm{sp}$. was $912 \mathrm{bp}$ long. This sequence included $493 \mathrm{bp}$ of the partial 18S rDNA region and the complete $419 \mathrm{bp}$-long ITS1 region. The sequence of the partial $28 \mathrm{~S}$ region was 847 bp long. No intraspecific variability was found in the 18S-ITS1 and 28S sequences.

\section{Quadriacanthus mandibulatus Francová \& Řehulková n. sp.}

Type-host: Heterobranchus bidorsalis Geoffroy SaintHilaire (Clariidae).

Type-locality: Nile River Basin, Sudan (locality 5).

Other locality: Lake Turkana, Kenya (locality 3 ).

Type-material: Holotype: MNHN HEL635. Paratypes: MNHN HEL635 (1 specimen); MNHN HEL636 (1 specimen); IPCAS M-635 (1 specimen).

Voucher material: MNHN HEL637 (3 specimens; locality 3); IPCAS M-635 (2 specimens; locality 3). Hologenophore: MNHN HEL644 (locality 5).

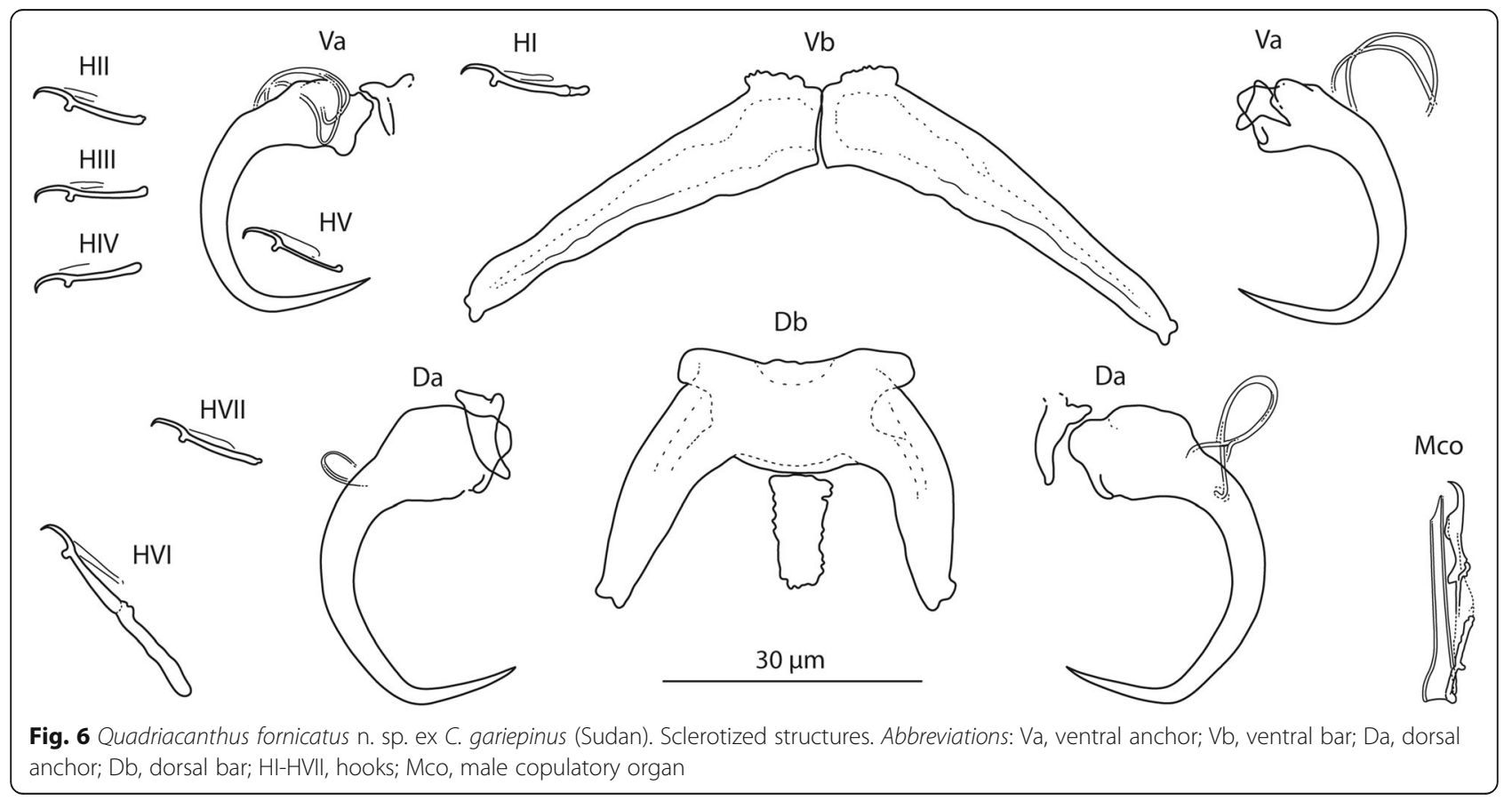


Comparative material examined: Type-specimens of Quadriacanthus thysi N'Douba, Lambert \& Euzet, 1999 (holotype MNHN 577 HF Tk 94; paratypes 576 HF Tk 93 and MRAC 37416).

Site in host: Gill lamellae.

Representative DNA sequences: 18S-ITS1 rDNA (GenBank acc. no. KX713996) and 28S rDNA (GenBank acc. no. KX685954) (see also Table 2).

ZooBank registration: To comply with the regulations set out in article 8.5 of the amended 2012 version of the International Code of Zoological Nomenclature (ICZN) [37], details of the new species have been submitted to ZooBank. The Life Science Identifier (LSID) of the article is urn:lsid:zoobank.org:pub:ADCB9E56-E8F1-48B6-AD21BBA5E52D0B39. The LSID for the new name Quadriacanthus mandibulatus $\mathrm{n}$. sp. is urn:lsid:zoobank.org:act: AD61A17B-E49C-49B6-B47F-A5CCA2EDD221.

Etymology: The specific name is derived from Latin ( mandibula $=$ an insect mandible; treated as an adjective) and reflects the insect mandible appearance of the dorsal bar process.

\section{Description}

[Based on 10 flattened and 5 unflattened specimens in GAP; Fig. 7]. Body length 569-840 (734; $n=5)$; greatest width 132-148 (139; $n=5)$. Haptor 140-184 (158; $n=5)$ long, $164-192(178 ; n=5)$ wide. Ventral anchor with narrow base, shaft sharply (at about $90^{\circ}$ ) bent medially, slightly recurved (poorly differentiated) point; accessory sclerite Y-shaped, with two subequal wing-like processes; $\mathrm{a}=28-30(29 ; n=10) ; \mathrm{b}=12-14$ (13; $n=10) ; \mathrm{c}=9-15(13 ; n=10) ; \mathrm{x} / \mathrm{y}=1.0-1.3(1.1 ;$ $n=10)$. Dorsal anchor with small base, elongated shaft bent (at about $90^{\circ}$ ) proximally and waved distally, short recurved point; accessory sclerite triangular; $\mathrm{a}=72-86$ $(79 ; n=10) ; \mathrm{b}=8-9(8 ; n=10) ; \mathrm{c}=24-27(26 ; n=10)$; $\mathrm{x} / \mathrm{y}=0.9-1.4(1.1 ; n=10)$. Ventral bar composed of two elongated components articulating medially; $d=54-68$ (62; $n=10$ ). Dorsal bar broadly V-shaped, with small anterior shield; large mid-posterior process, an insect mandible-like sclerotized structure distally passing into a lightly sclerotized membrane (often with a needle-like distal margin); e $=84-102(95 ; n=10) ; \mathrm{f}=28-41$ (34; $n=10) ; \mathrm{g}=12-18(15 ; n=10) ; \mathrm{h}=13-17(15 ; n=6)$. Hooks: 7 pairs, dissimilar in size; $i=12-74(28 ; n=10)$ : hook I 14-18 (16; $n=10)$; hooks II-V 12-17 (14; $n=10)$; hook VI $67-74(70 ; n=10)$; hook VII $49-56$ (52; $n=10)$. Vagina not observed. MCO comprising copulatory tube and accessory piece; $\mathrm{k}=70-79$ (74; $n=10$ ). Copulatory tube a broad slightly curved tube with spoon-like base and subterminal flange; $1=66-71$ $(69 ; n=10)$. Accessory piece articulated to the base of the copulatory tube, with constricted medial part and hook-shaped terminal portion.






\section{Differential diagnosis}

Based on the comparative morphology of the haptoral sclerites, Q. mandibulatus n. sp. resembles Quadriacanthus thysi described on the gills of Heterobranchus longifilis (Agnéby River, Ivory Coast) by N’Douba et al. [36]. The new species differs from the latter species by possessing a lightly sclerotized (poorly differentiated or needle-like) distal part of the supporting membrane of the dorsal bar (the distal part of the supporting membrane is fimbriated in Q. thysi) and from all other congeneric species by having a comparatively broad copulatory tube with subterminal flange.

\section{Molecular characterization}

The sequence of the 18S-ITS1 region of Q. mandibulatus n. sp. was 879 bp long, of which 500 bp corresponded to the partial $18 \mathrm{~S}$ rDNA region and $379 \mathrm{bp}$ corresponded to the ITS1 region. The sequence of the partial $28 \mathrm{~S}$ region was $777 \mathrm{bp}$ long. No intraspecific variability was found in the 18S-ITS1 and 28S sequences.

\section{Quadriacanthus pravus Francová \& Řehulková n. sp.}

Type-host: Clarias gariepinus (Burchell) (Clariidae). Type-locality: Nile River Basin, Sudan (locality 5).

Other locality: Nile River Basin, Sudan (locality 4).
Type-material: Holotype: MNHN HEL638. Paratype: IPCAS M-636 (1 specimen).

Voucher material: MNHN HEL639 (1 specimen; locality 4). Hologenophore: MNHN HEL645 (locality 5).

Comparative material examined: Voucher specimen of Quadriacanthus numidus Kritsky \& Kulo, 1988 (MNHN 146 HF).

Site in host: Gill lamellae.

Representative DNA sequences: 18S-ITS1 rDNA (GenBank acc. no. KX713997) and 28S rDNA (GenBank acc. no. KX685955) (see also Table 2).

ZooBank registration: To comply with the regulations set out in article 8.5 of the amended 2012 version of the International Code of Zoological Nomenclature (ICZN) [37], details of the new species have been submitted to ZooBank. The Life Science Identifier (LSID) of the article is urn:lsid:zoobank.org:pub:ADCB9E56-E8F1-48B6AD21-BBA5E52D0B39. The LSID for the new name Quadriacanthus pravus n. sp. is urn:lsid:zoobank.org :act:11D623F6-CA7D-434F-AB7C-28D44D17C0A5.

Etymology: The specific name is derived from Latin (pravus $=$ crooked, distorted, deformed) and refers to the shape of the ventral anchor point.

\section{Description}

[Based on 4 flattened and 2 unflattened specimens in GAP; Fig. 8]. Body length $580-589(585 ; n=2)$; greatest width

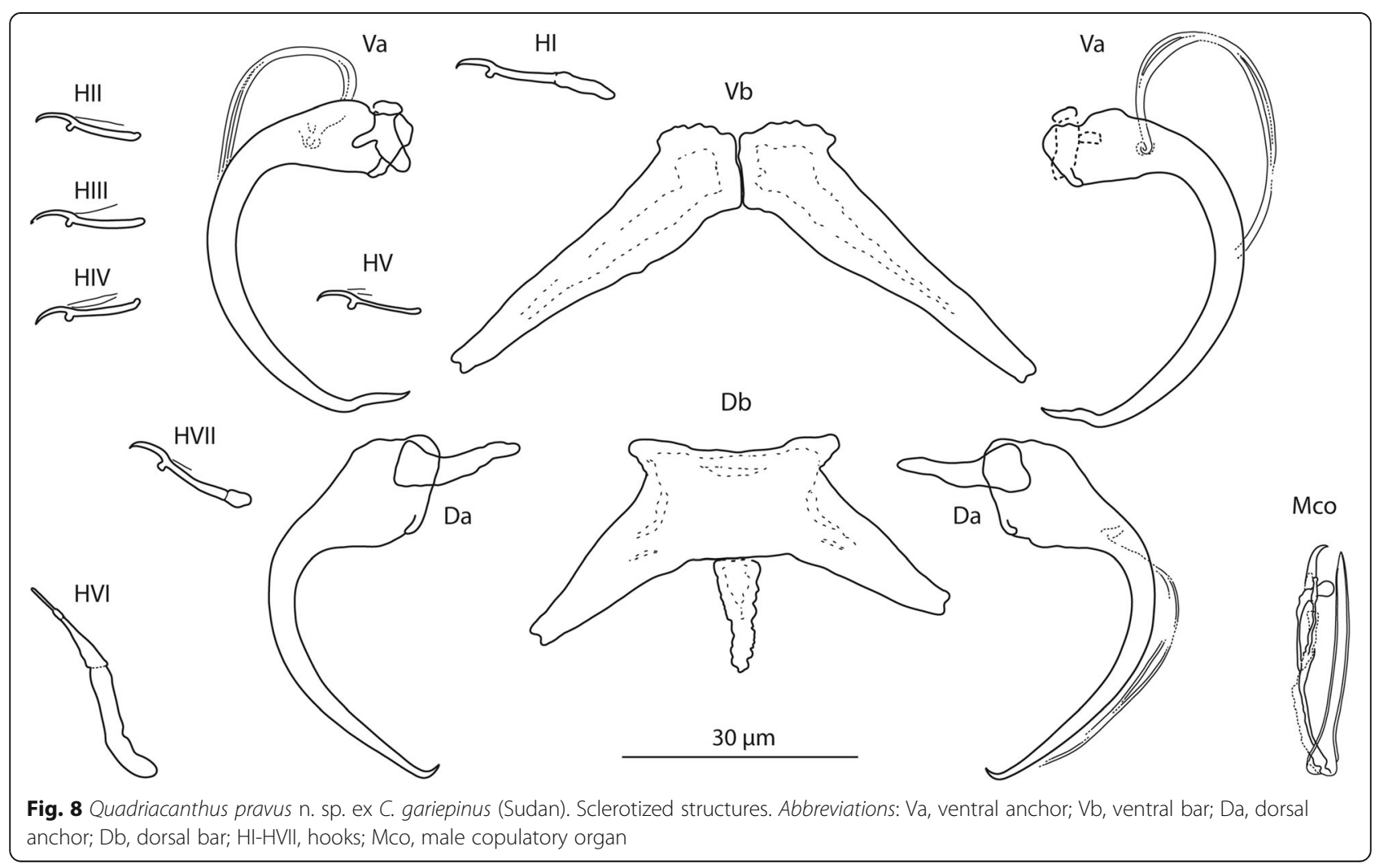


98-144 (121; $n=2)$. Haptor 78-108 (93; $n=2)$ long, $111-$ $162(136 ; n=2)$ wide. Ventral anchor with small base, long evenly curved shaft; doubly recurved (waved) point; accessory sclerite small, wings unequal; $a=39-40$ (40; $n=4) ; \mathrm{b}=8-9(8 ; n=4) ; \mathrm{c}=8-10(9 ; n=3) ; \mathrm{x} / \mathrm{y}=1.4-1.6$ $(1.5 ; n=4)$. Dorsal anchor with relatively broad base, bent shaft; tiny point; accessory sclerite triangular; $\mathrm{a}=41-44$ $(43 ; n=4) ; \mathrm{b}=2-3(2 ; n=4) ; \mathrm{c}=15-17(16 ; n=4) ; \mathrm{x} /$ $\mathrm{y}=1.0-1.0(1.0 ; n=4)$. Ventral bar composed of two rapidly tapering components; $d=38-44(41 ; n=4)$. Dorsal bar with small anterior shield; mid-posterior process triangular, with uneven margin: $\mathrm{e}=47-53(50 ; n=4)$; $\mathrm{f}=25-26(26 ; n=4) ; \mathrm{g}=11-14(12 ; n=4) ; \mathrm{h}=11-15$ $(13 ; n=4)$. Hooks: 7 pairs, dissimilar in size; $i=12-29$ $(17 ; n=2)$ : hook I 19-21 $(20 ; n=3)$, hooks II-V 12-14 $(13 ; n=2)$; hook VI $28-29(28 ; n=4)$, hook VII $16-17$ $(17 ; n=4)$. Vagina not observed. MCO comprising copulatory tube and accessory piece; $\mathrm{k}=29-32$ (30; $n=4)$. Copulatory tube a short lightly curved tube; length $27-30(28 ; n=4)$. Accessory piece articulated to base of the copulatory tube; proximal part rodshaped (usually lightly sclerotized); medial part complex; distal part with terminal hook and subterminal pestle.

\section{Differential diagnosis}

Quadriacanthus pravus n. sp. resembles the following species by its ventral anchor having a doubly recurved point: Q. ashuri Kritsky \& Kulo, 1988; Q. numidus Kritsky \& Kulo, 1988; Q. papernai Kritsky \& Kulo, 1988; and Q. gourenei N'Douba, Lambert \& Euzet, 1999 [5, 36]. It differs from $Q$. gourenei and $Q$. papernai by the ventral bar possessing longer (rapidly tapering) components, and is easily differentiated from Q. ashuri by having a ventral anchor with a longer shaft. The new species most closely resembles $Q$. numidus in the morphometry of the haptoral sclerites; in particular, the ventral anchor of both species is characteristic by having a relatively small base and markedly long evenly curved shaft, and by lacking a sclerotized vagina. However, Q. pravus n. sp. differs from $Q$. numidus in the shape of the accessory sclerite of the dorsal anchor (triangular in Q. pravus vs wing-shaped in Q. numidus), and in having an MCO characterized by an accessory piece with a terminal hook and subterminal pestle (an accessory piece lamellate in Q. numidus). Douëllou \& Chishawa [28] reported that the accessory piece of the MCO of their specimens, identified as Q. numidus, was slightly different from that described by Kritsky \& Kulo [5]. According to Douëllou \& Chishawa's [28] characterization and depiction, it seems that their specimens are conspecific with our specimens $(Q$. pravus n. sp.) rather than with the Q. numidus specimens of Kritsky \& Kulo [5]. However, because of the poor condition of the slide (MNHN $146 \mathrm{HF}$ ), the MCO could not be observed in any of the two voucher specimens. Thus, we hesitate to formally synonymize Q. numidus of Douëllou \& Chishawa [28] with Q. pravus n. sp. at this time.

\section{Molecular characterization}

The sequence of the $18 \mathrm{~S}-\mathrm{ITS} 1$ region of Q. pravus $\mathrm{n}$. sp. was 919 bp long, of which 514 bp corresponded to the partial 18S rDNA region and 405 bp corresponded to the entire ITS1 region. The sequence of the partial $28 \mathrm{~S}$ region was 799 bp long. No intraspecific variability was found in the 18S-ITS1 and 28S sequences.

\section{Quadriacanthus zuheiri Francová \& Řehulková n. sp.}

Type-host: Clarias gariepinus (Burchell) (Clariidae). Type-locality: Nile River Basin, Sudan (locality 5). Other locality: Nile River Basin, Sudan (locality 4). Type-material: Holotype: MNHN HEL640.

Voucher material: MNHN HEL639 (1 specimen; locality 4); IPCAS M-637 (2 specimens; locality 4). Hologenophore: MHHN HEL646 (locality 5).

Comparative material examined: Type-specimens of Quadriacanthus agnebiensis N’Douba, Lambert \& Euzet, 1999 (holotype and two paratypes MNHN $572 \mathrm{HF}$ Tk 89).

Site in host: Gill lamellae.

Representative DNA sequences: 18S-ITS1 rDNA (GenBank acc. no. KX713998) and 28S rDNA (GenBank acc. no. KX685956) (see also Table 2).

ZooBank registration: To comply with the regulations set out in article 8.5 of the amended 2012 version of the International Code of Zoological Nomenclature (ICZN) [37], details of the new species have been submitted to ZooBank. The Life Science Identifier (LSID) of the article is urn:lsid:zoobank.org:pub:ADCB9E56-E8F1-48B6AD21-BBA5E52D0B39. The LSID for the new name Quadriacanthus zuheiri n. sp. is urn:lsid:zoobank.org :act:A725FAF7-9AAF-4156-9647-6AE3EB7A0BCC.

Etymology: This species is named in honour to Prof. Zuheir N. Mahmoud of the Department of Zoology, Faculty of Science, University of Khartoum, Khartoum, Sudan, for his valuable and kind assistance during our field campaigns in Sudan.

\section{Description}

[Based on 6 flattened and 2 unflattened specimens in GAP; Fig. 9] Body length 600-690 (645; $n=2)$; greatest width $124-140(132 ; n=2)$. Haptor $95-113(104 ; n=2)$ long, $124-125(124 ; n=2)$ wide. Ventral anchor with moderate base, slightly curved shaft, long point; accessory sclerite small, with subequal wings; $a=37-38$ 


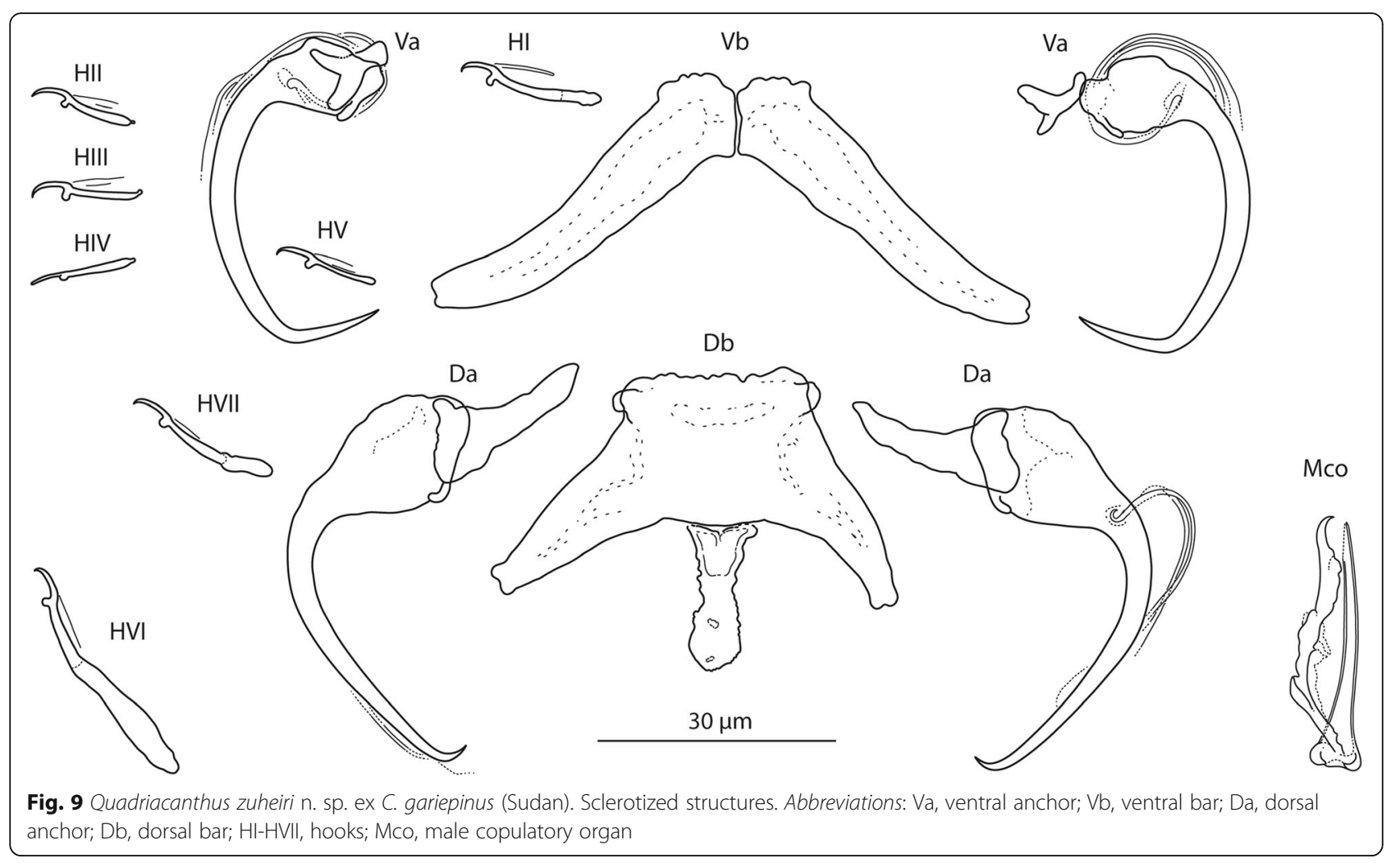

$(37 ; n=6) ; \mathrm{b}=10-11(11 ; n=6) ; \mathrm{c}=8-11(9 ; n=6)$; $\mathrm{x} / \mathrm{y}=1.1-1.6(1.4 ; n=6)$. Dorsal anchor with large base, shaft bent proximally, tiny point; accessory sclerite large, triangular; $\mathrm{a}=43-47(45 ; n=6) ; \mathrm{b}=2-3(3 ; n=6)$; $\mathrm{c}=18-22(20 ; n=6) ; \mathrm{x} / \mathrm{y}=1.0-1.3(1.1 ; n=6)$. Ventral bar composed of two elongated components; $d=39-44$ $(41 ; n=5)$. Dorsal bar with small anterior shield; midposterior process tongue-like, with uneven margin; $\mathrm{e}=42-51(46 ; n=5) ; \mathrm{f}=24-32(29 ; n=6) ; \mathrm{g}=13-18$ $(15 ; n=6) ; \mathrm{h}=11-18(14 ; n=5)$. Hooks: 7 pairs, dissimilar in size; $i=12-31(17 ; n=5)$ : hook I 17-18 (18; $n=6)$, hooks II-V 12-14 (13; $n=5)$, hook VI 27-31 $(29 ; n=6)$, hook VII $19-19(19 ; n=6)$. Vagina not observed. MCO comprising copulatory tube and accessory piece; $\mathrm{k}=30-34(32 ; n=6)$. Copulatory tube straight to slightly curved; base with thickened margins; $1=28-30$ $(30 ; n=6)$. Accessory piece basally articulated to the copulatory tube; medial part formed as a clamp jaw; hookshaped termination serving as a guide for distal portion of the copulatory tube.

\section{Differential diagnosis}

Based on the comparative morphology of the haptoral sclerites, Q. zuheiri n. sp. most closely resembles $Q$. aegypticus El-Naggar \& Serag, 1986, and may also be confused with Q. agnebiensis N'Douba, Lambert \& Euzet, 1999, a parasite of Heterobranchus isopterus from Ivory Coast [27, 36]. Quadriacanthus zuheiri n. sp. differs from Q. aegypticus by having a noticeably smaller MCO composed of a copulatory tube without basal flange (with flange in Q. aegypticus) and simpler accessory piece (i.e. without two medial diverticula and distal hooks). Examination of the holotype and two paratypes of $Q$. agnebiensis showed that Q. zuheiri n. sp. differs from the latter species by possessing: (i) a longer ventral anchor with less arched shaft; (ii) a larger accessory sclerite on the part of the dorsal anchor; (iii) shorter and less robust hooks VI and VII; and (iv) an accessory piece with more complex medial part (formed as a lightly sclerotized clamp jaw) and hooked (double hooked in Q. agnebiensis) distal termination.

\section{Molecular characterization}

The sequence of the 18S-ITS1 region of Q. zuheiri n. sp. was 877 bp long, of which 469 bp corresponded to the $18 \mathrm{~S}$ rDNA region and 408 bp corresponded to the ITS1 region. The sequence of the partial $28 \mathrm{~S}$ region was 772 bp long. No intraspecific variability was found in the 18S-ITS1 and 28S sequences.

\section{Interspecific genetic relationships within genus Quadriacanthus}

No intraspecific variability was detected for the $18 \mathrm{~S}$ ITS1 and 28S regions. The overall K2P mean genetic distance was $10.34 \%$ for the $18 \mathrm{~S}$-ITS1 sequences and 
$3.32 \%$ for the $28 \mathrm{~S}$ rDNA sequences. The pairwise genetic distances are presented in Table 3. Among the Quadriacanthus species, Q. clariadis exhibited the lowest genetic divergence from Q. bagrae (1.89\% for 18S-ITS1, 0.92\% for 28S). Q. mandibulatus n. sp. and Q. fornicatus n. sp. exhibited the greatest genetic distances (5.87\%) for $28 \mathrm{~S}$ rDNA sequences, and Q. mandibulatus n. sp. and $Q$. bagrae represented the most divergent species pair for 18S-ITS1 sequences (13.95\%; Table 3).

An unambiguous alignment of 18S-ITS1 sequences spanned 799 positions, of which 275 positions were variable. The $28 \mathrm{~S}$ alignment contained a total of 725 bp with 246 variable characters. The phylogenetic trees of Quadriacanthus species parasitizing East African freshwater siluriform fishes inferred from 18S-ITS1 and 28S fragments had very similar topologies (Fig. 10). In both gene trees, Q. bagrae showed a sister relationship to Q. clariadis and Q. fornicatus n. sp.; Q. zuheiri n. sp. was sister to Q. pravus n. sp. For 28S, Q. mandibulatus n. sp. formed a separate clade (occupying a basal position); for 18S, Q. mandibulatus $\mathrm{n}$. sp. formed one clade with $Q$. zuheiri $\mathrm{n}$. sp. and Q. pravus n. sp. Moreover, the phylogenetic analysis of 18S-ITS1 rRNA gene sequences revealed identity between Q. mandibulatus n. sp. and Quadriacanthus sp. retrieved from GenBank (they differed in one nucleotide). Therefore, we consider this Quadriacanthus sp. with the HG491496 sequence, isolated from the airbreathing clariid Heterobranchus bidorsalis in Senegal (Šimková, pers. com.), as a representative of $Q$. mandibulatus n. sp.

\section{Discussion}

The geographical distributions and host preferences of species of Quadriacanthus suggest an interesting evolutionary history of the group. Species of Quadriacanthus have been confirmed as parasites of fishes representing three families, namely the Clariidae, Bagridae (Siluriformes), and Notopteridae (Osteoglossiformes) [2, 3]. Clariid catfishes most likely originated in Asia 40-50 MY ago but contemporary African and Asian species originated from a common ancestor that was present on the Arabian plate about $15 \mathrm{MY}$ ago [38]. From that moment, the ancestral species came back to Asia and colonized Africa probably through brackish water bridges like lagoons [39]. Species of Quadriacanthus infesting clariids occur in the freshwaters of Africa, India, Malaysia, Thailand, China and Vietnam [2, 7]. Inasmuch as members of dactylogyrid genera are generally considered highly host-specific (usually confined to members of a single host family), the wide geographical distribution of Quadriacanthus spp. on clariid hosts suggests comparatively old host-parasite relationships, i.e. lasting at least $15 \mathrm{MY}$. On the other hand, formulating a hypothesis on the origin of Quadriacanthus species on bagrids (B. bajad, B. docmak and B. orientalis) in Africa is more problematical. Species of Quadriacanthus have not been found on bagrids in Asia, although these fishes have occasionally been examined for gill parasites [2]. The family Bagridae was poorly defined until its revision by Mo [40] and de Pinna [41], who established the families Austroglanididae, Claroteidae and Auchenoglanididae for all African genera (except Bagrus!) previously considered members of the Bagridae [42]. The wellknown Farenholz' rule states that the natural classification of some parasite groups usually corresponds directly with the natural relationships of their hosts [43]. Indeed, species of claroteids and auchenoglanidids are known to harbour species of Protoancylodiscoides Paperna, 1969 and Bagrobdella Paperna, 1969, respectively, while those of Bagrus are known to be infected with one species of Quadriacanthus, i.e. Q. bagrae [2].

Some authors (e.g. Brooks \& McLennan [44]) believe that monogeneans possess characteristics that perfectly adapt them for surviving numerous host-switching events. Assuming that members of the Clariidae are the ancestral hosts of species of Quadriacanthus, the occurrence of $Q$. bagrae (while clearly a member of the genus) on African bagrid hosts probably resulted from host switching. Our phylogenetic reconstruction indicates that Q. bagrae is phylogenetically nested within the parasites from Clarias gariepinus at a derived position of the tree (Fig. 10). More specifically, Q. bagrae from Bagrus docmak is a sister species to Q. clariadis from C. gariepinus.

Table 3 Pairwise 18S-ITS1 (below diagonal) and 28S (above diagonal) nucleotide divergences for each observed Quadriacanthus spp. using K2P distance (\%)

\begin{tabular}{lllllll}
\hline & & 1 & 2 & 3 & 4 & 5 \\
2 & Quadriacanthus bagrae & & 0.92 & 2.93 & 4.88 & 2.12 \\
3 & Quadriacanthus clariadis & 1.89 & & 2.80 & 4.74 & 2.26 \\
4 & Quadriacanthus fornicatus n. sp. & 6.40 & 5.85 & & 5.87 & 2.94 \\
5 & Quadriacanthus mandibulatus n. sp. & 13.95 & 13.32 & 12.57 & & 4.80 \\
6 & Quadriacanthus pravus n. sp. & 13.48 & 13.01 & 12.58 & 10.05 & 4.73 \\
\hline
\end{tabular}




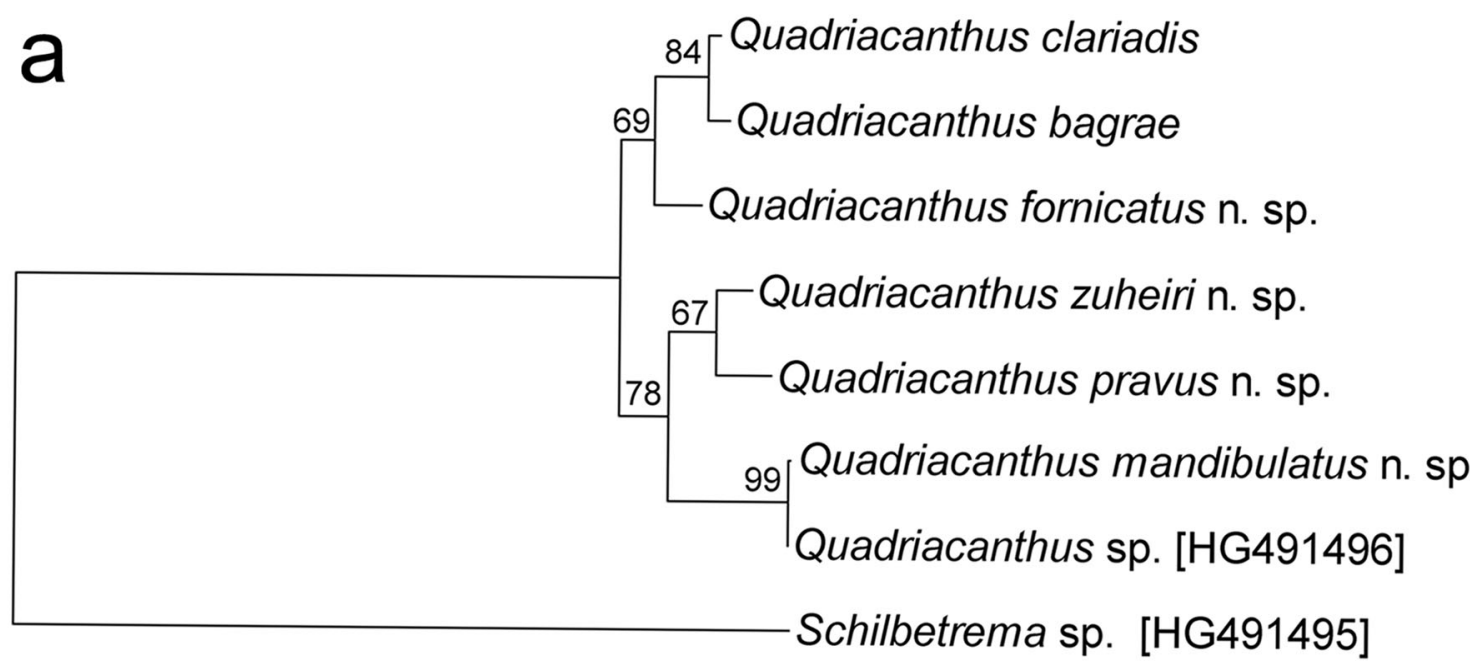

0.1 substitution/site

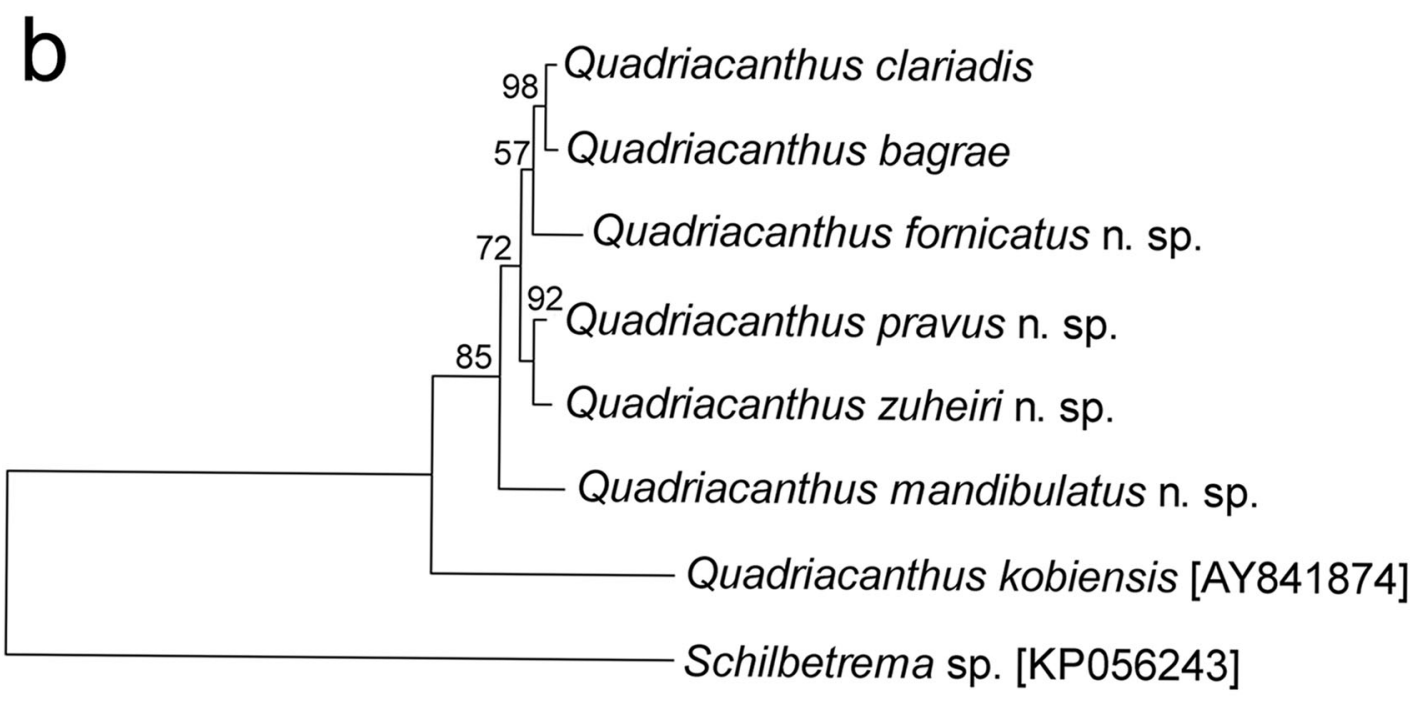

\subsection{5 substitution/site}

Fig. 10 Phylograms for Quadriacanthus species parasitizing African freshwater catfishes derived from maximum likelihood analysis using 18S-ITS1 (a) and 285 regions (b). Bootstrap values $>50 \%$ are shown along the branches. Accession numbers for dactylogyrid sequences retrieved from GenBank are shown in brackets

The clade is located at a derived position of the tree, suggesting that $Q$. bagrae (or its ancestor) transferred from clariids to species of Bagrus and not conversely. Several studies suggested that such lateral transfer (host switch) can occur both between related host species (e.g. [45]) and even between phylogenetically distant host species [46-48]. Recently, Nack et al. [3] hypothesized that the presence of Quadriacanthus euzeti Nack, Pariselle \& Bilong Bilong, 2015 on Papyrocranus afer (Notopteridae, Osteoglossiformes) is probably the result of a lateral transfer from species belonging to Clarias or Bagrus which live sympatrically with $P$. afer in Lake Ossa (South Cameroon). Although more data are needed to resolve phylogenetic relationships within Quadriacanthus, the occurrence of Q. bagrae on Bagrus docmak may represent a similar lateral transfer from a species of Clarias, probably C. gariepinus. Bagrus docmak inhabits, among other locations, the Nile River, where it lives in sympatry with Clarias gariepinus [9].

Although we cannot verify the accuracy of the identification, Q. bagrae was also recorded on C. gariepinus by some authors [5, 7]. Because the drawings of the MCO provided by these authors are insufficient for detailed 


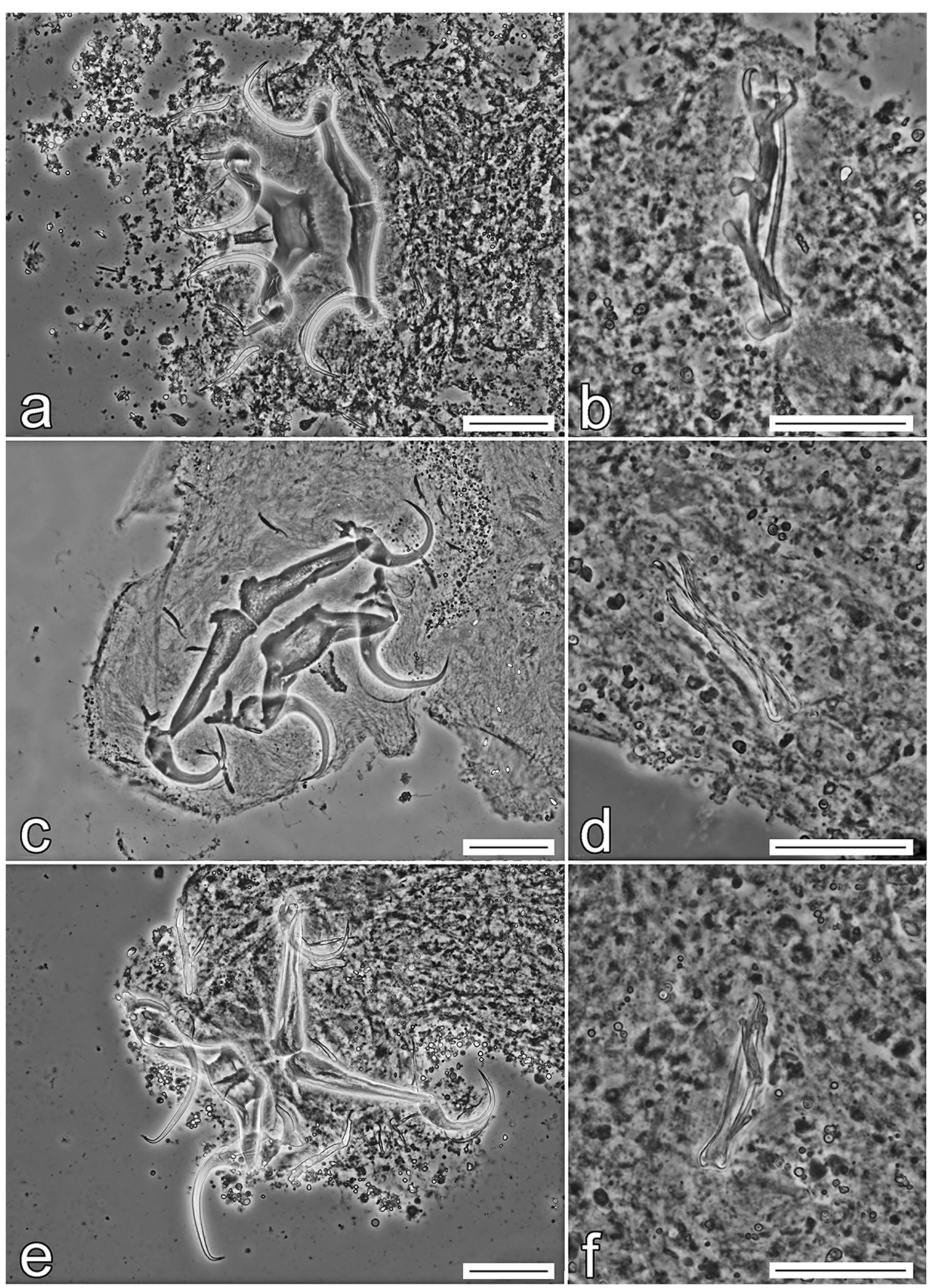

Fig. 11 Phase-contrast photomicrographs of the sclerotized haptoral structures and male copulatory organ of Quadriacanthus aegypticus (a, b), Q. bagrae (c, d), Q. clariadis (e, f). Scale-bars: a, c, e, $30 \mu \mathrm{m} ; \mathbf{b}, \mathbf{d}, \mathbf{f}, 20 \mu \mathrm{m}$ 



Fig. 12 Phase-contrast photomicrographs of the sclerotized haptoral structures and male copulatory organ of Quadriacanthus fornicatus n. sp. (a, b), Q. pravus n. sp. (c, d), Q. zuheiri n. sp. (e, f). Scale-bars: a, c, e, $30 \mu \mathrm{m} ; \mathbf{b}, \mathbf{d}, \mathbf{f}, 20 \mu \mathrm{m}$ 

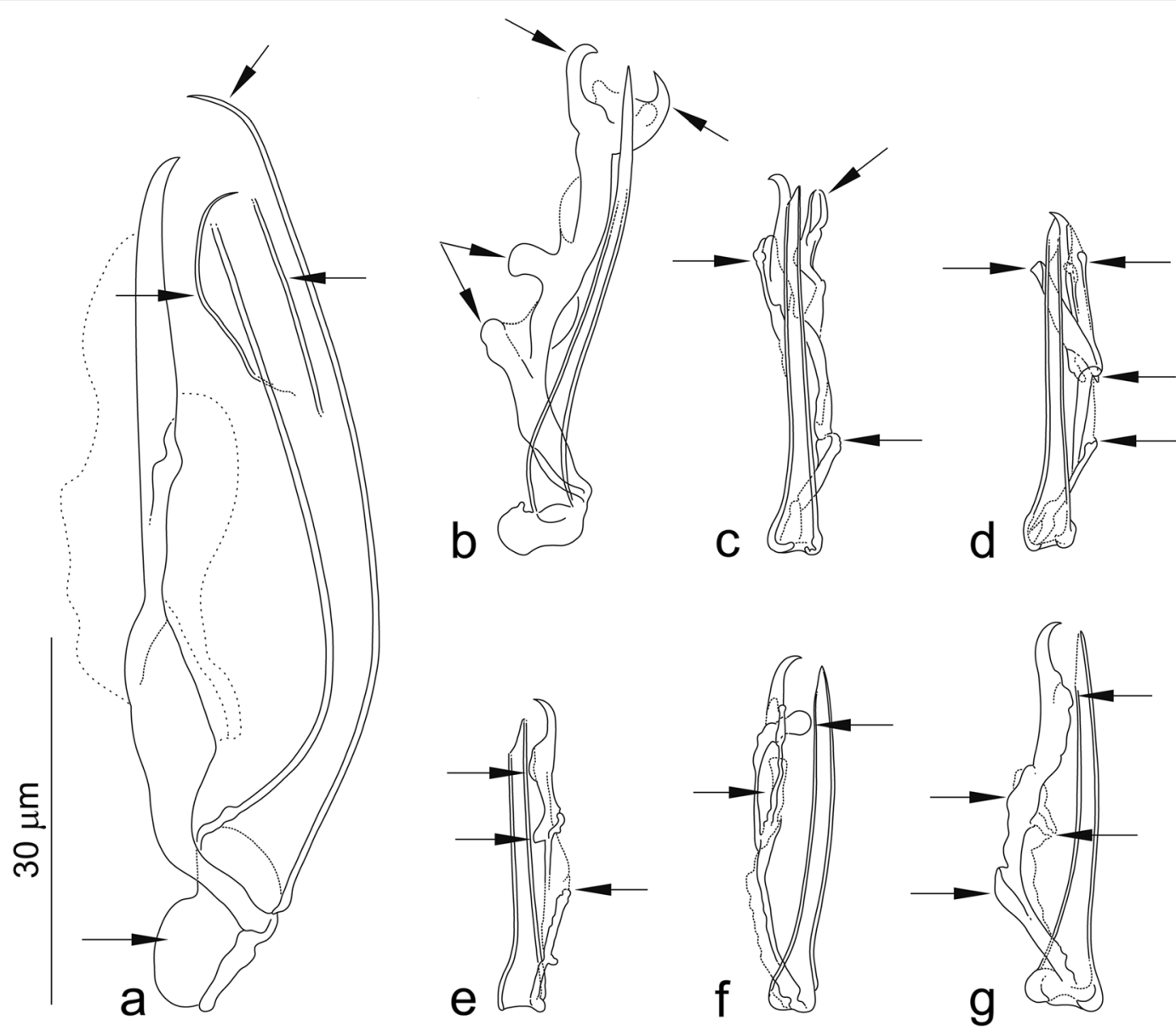

Fig. 13 Male copulatory organ of seven representative species of Quadriacanthus (characters of interest indicated by arrows). a $Q$. mandibulatus n. sp. b Q. aegypticus. c Q. bagrae. d Q. clariadis. e $Q$. fornicatus n. sp. f $Q$. pravus n. sp. g Q. zuheiri n. sp.

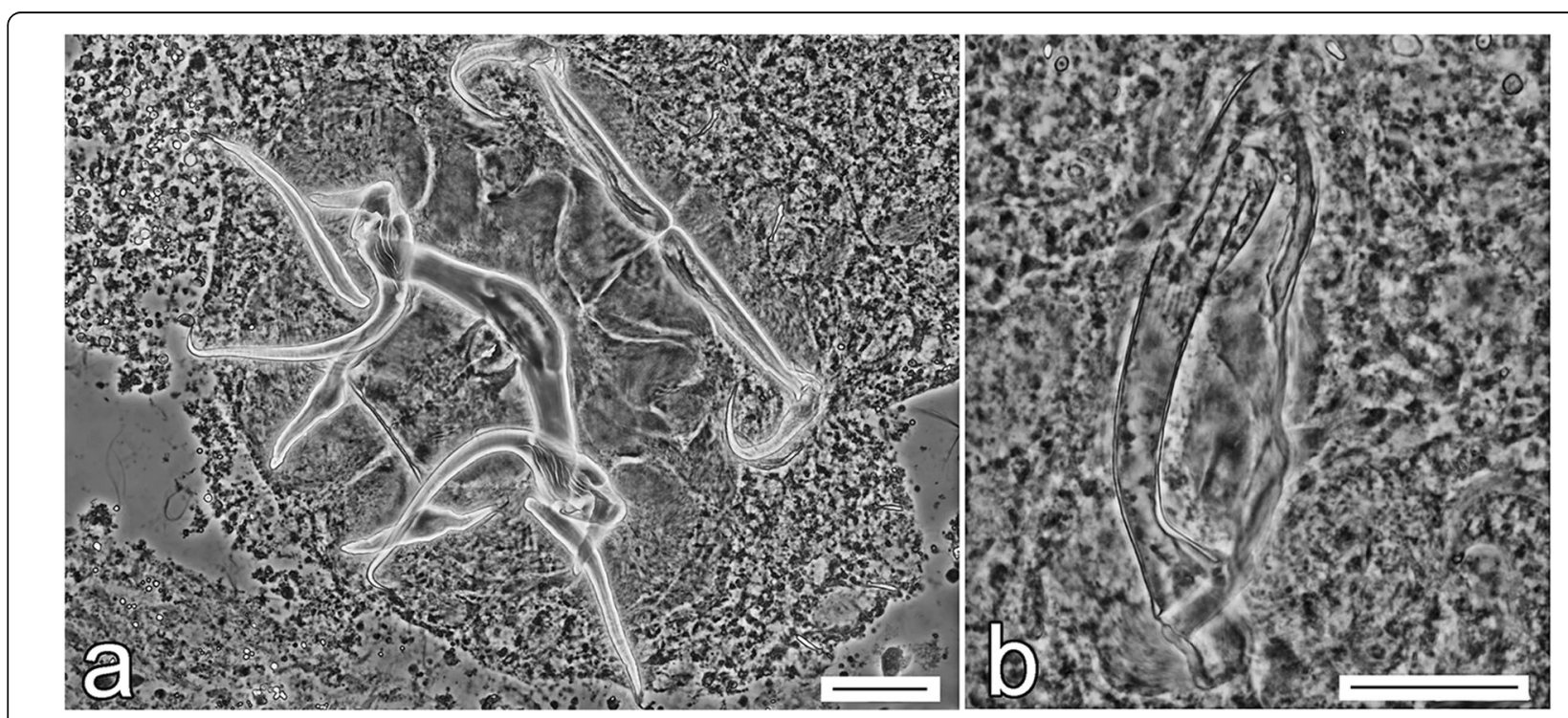

Fig. 14 Phase-contrast photomicrographs of the sclerotized structures of Quadriacanthus mandibulatus n. sp. a Haptoral structures. b Male copulatory organ. Scale-bars: $\mathbf{a}, 30 \mu \mathrm{m} ; \mathbf{b}, 20 \mu \mathrm{m}$ 
comparison with our specimens, confirmation of the records of Q. bagrae on C. gariepinus will depend on the collection and evaluation (morphological and molecular) of new parasite material from C. gariepinus. It will be interesting to see whether Q. bagrae on C. gariepinus is a genuine $Q$. bagrae (sensu stricto). If they represent two different species of Quadriacanthus, then the occurrence of Q. bagrae on Bagrus docmak may suggest, at this time, a case of host switching with speciation.

Until now, there were no studies on the genetic characteristics of Quadriacanthus spp.; thus, the molecular data presented here represent an important advance in the molecular identification and differentiation of this genus. In our study, molecular characterization is presented for six Quadriacanthus species (i.e. for all the species recorded in our study, except Q. aegypticus). The interspecific genetic relationships among Quadriacanthus spp. observed in this study are congruent with the similarity of the basic morphology of the sclerotized structures, especially of those of the MCO (Figs. 11, 12, 13). The separation of $Q$. mandibulatus $\mathrm{n}$. sp. from the other species corresponds with the different morphology of its copulatory tube. The copulatory tube is terminally enlarged and with a subterminal flange in $Q$. mandibulatus $\mathrm{n}$. sp., while the corresponding structure in all other congeners studied is comparatively small and with an oblique tapering termination (Figs. 13, 14).

\section{Conclusions}

This study suggests that species of Quadriacanthus parasitizing catfishes in the Old World provide useful models for the study of biogeography and coevolution. However, future studies are needed that would have to involve the examination of dactylogyrids from a greater number of host individuals and host species from a larger geographical area, the utilization of other monogenean taxa, and the incorporation of a homologous series of host features into the matrix derived from the parasite cladogram.

\section{Abbreviations \\ GAP: Glycerine and ammonium picrate; ITS1: Internal transcribed spacer 1; K2: Kimura 2-parameter; MCO: Male copulatory organ; MNHN: Muséum National d'Historie Naturelle; MRAC: Musée Royal de l'Afrique Centrale; PCR: Polymerase chain reaction}

\section{Acknowledgements}

We thank David Lotuliakou, John O. Malala (KMFRI, Lake Turkana Station, Kenya) and Miloslav Jirků (Institute of Parasitology, AS CR, Czech Republic) for logistical support throughout the field sampling. We also are indebted to Matej Polačik (Institute of Vertebrate Biology, AS CR, Czech Republic) for help with fish sampling in Sudan, and to Šárka Mašová, Iva Přikrylová and Maria Lujza Kičinjaová (Department of Botany and Zoology, Masaryk University, Czech Republic) for help with monogenean collection. Big thanks go to Ondřej Hájek (Department of Botany and Zoology, Masaryk University, Czech Republic) for making the map with the sampling sites. Our thanks also go to Jean-Lou Justine (Muséum National d'Historie Naturelle, France) and Maarten P. Vanhove (Musée Royal de l'Afrique Centrale, Belgium) for the kind loan of type-material. We are very grateful to Delane C. Kritsky (Idaho State University, USA) who carefully revised the submitted manuscript and gave us valuable advice.

\section{Funding}

This study was financially supported by ECIP (European Centre of Ichthyoparasitology) - Centre of Excellence, Grant Agency of the Czech Republic, No. P505/12/G112.

\section{Availability of data and materials}

The data supporting the conclusions of this article are included within the article. The parasitological material is deposited in the Helminth collection of the Muséum National d'Histoire Naturelle, Paris, France (MNHN), and the Helminthological collection of the Institute of Parasitology, Academy of Sciences of the Czech Republic, České Budějovice, Czech Republic (IPCAS). The molecular datasets generated during the present study are available in the GenBank repository under accession numbers KX713993-KX713998 and KX685951-KX685956.

\section{Authors' contributions}

EǨ designed this study. KF, ĚR performed the morphological characterization and described the species. MS performed molecular analyses. EŘ, KF and MS wrote the paper. RB identified fish species, contributed to fish sampling in Lake Turkana, White and Blue Nile. MG provided scientific background in the field of monogenean research. ZNM and MG revised the manuscript. All authors read and approved the final manuscript.

\section{Competing interests}

The authors declare that they have no competing interests.

\section{Consent for publication}

Not applicable.

\section{Ethics approval}

The research was approved by the Ethics Committee of Masaryk University. The approval number which allows us to work with vertebrate animals is cZ01302.

\section{Publisher's Note}

Springer Nature remains neutral with regard to jurisdictional claims in published maps and institutional affiliations.

\section{Author details}

${ }^{1}$ Department of Botany and Zoology, Faculty of Science, Masaryk University, Kotlářská 2, 61137 Brno, Czech Republic. ' Institute of Vertebrate Biology, Academy of Sciences of the Czech Republic, Květná 8, 60365 Brno, Czech Republic. ${ }^{3}$ Department of Zoology, Faculty of Science, University of Khartoum, Khartoum, Sudan.

Received: 19 November 2016 Accepted: 26 May 2017 Published online: 01 August 2017

References

1. Poulin R. The evolution of monogenean diversity. Int J Parasitol. 2002;32(3): 245-54.

2. Lim LHS, Timofeeva TA, Gibson DI. Dactylogyridean monogeneans of the siluriform fishes of the old world. Syst Parasitol. 2001;50(3):159-97.

3. Nack J, Bitja Nyom AR, Pariselle A, Bilong Bilong CF. New evidence of a lateral transfer of monogenean parasite between distant fish hosts in Lake Ossa, South Cameroon: the case of Quadriacanthus euzeti n. sp. J Helminthol. 2016;90(4):455-9.

4. Paperna I. Studies on monogenetic trematodes in Israel. 3. Monogenetic trematodes of the Cyprinidae and Clariidae of the Lake of Galilee. Bamidgeh. 1961;13:14-29.

5. Kritsky DC, Kulo SD. The African species of Quadriacanthus with proposal of Quadriacanthoides gen. n. (Monogenea: Dactylogyridae). Proc Helminthol Soc Wash. 1988;55(2):175-87.

6. Dubey A, Gupta AK, Agarwal SM. Studies on monogenean parasites in fresh water fishes at Raipur IV. Taxonomic discussion on scope of Quadriacanthus Paperna, 1961. A new genus Anacornuatus and two new species from Clarias batrachus at Raipur. Indian J Helminthol. 1992;43(1991):27-34.

7. Tripathi A, Agrawal N, Pandey KC. The status of Quadriacanthus Paperna, 1961 and Anacornuatus Dubey et al., 1991 (Monogenoidea: Dactylogyridae) with redescription of Q. kobiensis ha Ky, 1968, new geographical records for Q. bagrae Paperna, 1979 and Q. clariadis Paperna, 1961 from India and a note on speciation in Monogenoidea. Parasitol Int. 2007:56(1):23-30. 
8. Bahanak DND, Nack J, Pariselle A, Bilong Bilong CF. Description of three new species of Quadriacanthus (Monogenea: Ancyrocephalidae) gill parasites of Clarias submarginatus (Siluriformes: Clariidae) from Lake Ossa (littoral region, Cameroon). Zoologia. 2016;33(4):e20160044.

9. Bailey RG. Guide to the fishes of the River Nile in the Republic of the Sudan. J Nat Hist. 1994;28:937-70.

10. Hopson AJ, Hopson J. The fishes of Lake Turkana with a description of three new species: Alestes ferox sp. nov., Alestes minutus sp. nov. (Pisces: Characidae) and Barbus turkanae sp. nov. (Pisces: Cyprinidae). In: Hopson AJ, editor. Lake Turkana. A report on the findings of the Lake Turkana project 1972-1975. London: Overseas Development Administration; 1982. p. 283-347.

11. Froese R, Pauly D, editors. FishBase. 2016. http://www.fishbase.org/search.php. Accessed 01 Nov 2016

12. Eschmeyer WN, Fricke R, van der Laan R. Catalog of fishes: genera, species, references. 2016. http://researcharchive.calacademy.org/research/ ichthyology/catalog/fishcatmain.asp. Accessed 01 Nov 2016.

13. Musilová N, Řehulková E, Gelnar M. Dactylogyrids (Platyhelminthes: Monogenea) from the gills of the African carp, Labeo coubie Rüppell (Cyprinidae), from Senegal, with descriptions of three new species of Dactylogyrus and the redescription of Dactylogyrus cyclocirrus Paperna, 1973. Zootaxa. 2009:2241:47-68.

14. Pleijel R, Jondelius U, Norlinder E, Nygeren A, Oxelman B, Schander C, et al. Phylogenies without roots? A plea for the use of vouchers in molecular phylogenetic studies. Mol Phylogenet Evol. 2008;48:369-71.

15. Řehulková E, Gelnar M. A revised diagnosis of Thylacicleidus (Monogenea: Dactylogyridae) with a redescription of the type species, Thylacicleidus serendipitus, and descriptions of two new species from southeast Asian pufferfishes (Tetraodontiformes: Tetraodontidae). J Parasitol. 2005;91(4):794-807.

16. Mizelle JD. New species of trematodes from the gills of Illinois fishes. Amer Midl Nat. 1936;17:785-806.

17. International Commission on Zoological Nomenclature. Article 50. Authors of names and nomenclatural acts. In: International Code of Zoological Nomenclature online. 2016. http://www.nhm.ac.uk/hosted-sites/iczn/code/ index.jsp?article=50\&nfv=true. Accessed 01 Nov 2016.

18. Hassouna N, Michot B, Bachellerie JP. The complete nucleotide sequence of mouse $28 \mathrm{~S}$ rRNA gene. Implications for the process of size increase of the large subunit rRNA in higher eukaryotes. Nucleic Acids Res. 1984;12(8):3563-83.

19. Sinnappah ND, Lim LHS, Rohde K, Tinsley R, Combes C, Verneau O. A paedomorphic parasite associated with a neotenic amphibian host: phylogenetic evidence suggests a revised systematic position for Sphyranuridae within anuran and turtle Polystomatoineans. Mol Phylogenet Evol. 2001;18(2):189-201.

20. Šimková A, Plaisance L, Matějusová I, Morand S, Verneau O. Phylogenetic relationships of the Dactylogyridae Bychowsky, 1933 (Monogenea: Dactylogyridae): the need for the systematic revision of the Ancyrocephalinae Bychowsky, 1937. Syst Parasitol. 2003;54:1-11.

21. Mendlová M, Desdevises Y, Civáňová K, Pariselle A, Šimková A. Monogeneans of west African cichlid fish: evolution and cophylognetic interactions. PLoS One. 2012;7(5):e37268.

22. Thompson JD, Higgins DG, Gibson TJ. CLUSTAL W: improving the sensitivity of progressive multiple sequence alignment through sequence weighting, position-specific gap penalties and weight matrix choice. Nucleic Acids Res. 1994;22:4673-80.

23. Hall TA. BioEdit: a user-friendly biological sequence alignment editor and analysis program for windows 95/98/NT. Nucl Acids Symp Ser. 1999;41:95-8.

24. Capella-Gutiérrez S, Silla-Martínez JM, Gabaldón T. TrimAl: a tool for automated alignment trimming in large-scale phylogenetic analyses. Bioinformatics. 2009:25:1972-3.

25. Kimura M. A simple method for estimating evolutionary rate of base substitutions through comparative studies of nucleotide sequences. J Mol Evol. 1980;16:111-20.

26. Kumar S, Stecher G, Tamura K. MEGA7: molecular evolutionary genetics analysis version 7.0 for bigger datasets. Mol Biol Evol. 2016;33(7):1870-4.

27. El-Naggar MM, Serag HM. Quadriacanthus aegypticus n. sp., a monogenean gill parasite from the Egyptian teleost Clarias lazera. Syst Parasitol. 1986;8(2):129-40.

28. Douëllou L, Chishawa AMM. Monogeneans of three Siluriform fish species in Lake Kariba, Zimbabwe. J Afr Zool. 1995;109(2):99-115. (Erratum in J Afr Zool. 109(5/6):521-522)
29. Hassanain MA, Abu-El Ezz N, Shalaby SI, Ashour A, El-Aroussy N. Studies on some monogenean trematodes infecting Clarias gariepinus (Pisces: Clariidae) in Egypt. Egypt J Zool. 1999;33:373-86.

30. Madanire-Moyo GN, Luus-Powell WJ, Olivier PAS. Ecology of metazoan parasites of Clarias gariepinus (Osteichthyes: Clariidae) from the Nwanedi-Luphephe Dams of the Limpopo River System, South Africa. Afr Zool. 2010;45(2):233-43.

31. Crafford D, Luus-Powell W, Avenant-Oldewage A. Monogenean parasites from fishes of the Vaal dam, Gauteng Province, South Africa II. New locality records. Acta Parasitol. 2014;59(3):485-92.

32. Beletew M, Getahun A, Vanhove MPM. First report of monogenean flatworms from Lake Tana, Ethiopia: gill parasites of the commercially important Clarias gariepinus (Teleostei: Clariidae) and Oreochromis niloticus tana (Teleostei: Cichlidae). Parasit Vectors. 2016;9:410.

33. Paperna I. Monogenea of inland water fish in Africa. Ann Mus R Afr Cent. 1979;226:1-131.

34. El-Naggar MM, Serag HM. The monogenean Quadriacanthus kearni n. sp. and a report of Q. clariadis clariadis Paperna, 1979 on the gills of Clarias lazera in Nile Delta. J Egypt Soc Parasitol. 1985;15(2):479-92.

35. Molnár K, Mossalam I. Monogenean parasites from fishes of the Nile in Egypt. Parasitol Hung. 1985;18:5-10.

36. N'Douba V, Lambert A, Euzet L. Seven new species of Quadriacanthus Paperna, 1961 (Monogenea) from the gills of Heterobranchus longifilis and $H$. isopterus from the Ivory Coast, West Africa. Syst Parasitol. 1999;44:105-18.

37. International Commission on Zoological Nomenclature. Amendment of articles 8, 9, 10, 21 and 78 of the International code of Zoological Nomenclature to expand and refine methods of publication. Zootaxa. 2012;3450:1-7.

38. Otero O, Gayet M. Palaeoichthyofaunas from the lower Oligocene and Miocene of the Arabian plate: palaeoecological and palaeobiogeographical implications. Palaeogeogr Palaeoclimatol Palaeoecol. 2001;165(1-2):141-69.

39. Agnese J-F, Teugels GG. Insight into the phylogeny of African Clariidae (Teleostei, Siluriformes): implications for their body shape evolution, biogeography, and taxonomy. Mol Phylogenet Evol. 2005;36(3):546-53.

40. Mo TP. Anatomy, relationships and systematics of Bagridae (Teleostei), with a hypothesis of siluroid phylogeny. Theses Zool. 1991;17:1-216.

41. de Pinna MCC. Phylogenetic relationships of neotropical Siluriformes (Teleostei: Ostariophysi): historical overview and synthesis of hypotheses. In: Malabarba LR, Reis RE, Vari RP, Lucena ZMS, Lucena CAS, editors. Phylogeny and classification of Neotropical fishes. Porto Alegre: Edipucrs; 1998. p. 279-330.

42. Nelson JS. Fishes of the World. 4th ed. Hoboken, New Jersey: Wiley; 2006.

43. Eichler W. Some rules in ectoparasitism. Ann Mag Nat Hist. 1948;12:588-98.

44. Brooks DR, McLennan DA. Phylogeny, ecology and behavior. Chicago: University of Chicago Press; 1991.

45. Pariselle A, Boeger WA, Snoeks J, Bilong Bilong CF, Morand S, Vanhove MPM. The monogenean parasite fauna of cichlids: a potential tool for host biogeography. Int J Evol Biol. 2011;2011:15.

46. Zietara MS, Lumme J. Speciation by host switch and adaptive radiation in a fish parasite genus Gyrodactylus (Monogenea, Gyrodactylidae). Evolution. 2002;56(12):2445-58.

47. Messu Mandeng FD, Bilong Bilong CF, Pariselle A, Vanhove MPM, Bitja Nyom AR, Agnese J-F. A phylogeny of Cichlidogyrus spp. (Monogenea, Dactylogyridea) clarifies a host-switch between fish families and reveals an adaptive component to attachment organ morphology of this parasite genus. Parasit Vectors. 2015;8:582.

48. Vanhove MPM, Huyse T. Host-specificity and species-jumps in fish-parasite systems. In: Morand S, Krasnov B, Littlewood DTJ, editors. Parasite diversity and diversification: evolutionary ecology meets phylogenetics. Cambridge: Cambridge University Press; 2015. p. 401-19. 